\title{
Considerations in the Application of the Electronic Dosimeter to Dose of Record
}

Manuscript Completed: November 1997

Date Published: December 1997

Prepared by

K. L. Swinth

Swinth Associates

2177 Cascade

Richland, WA 99352

D. Nellis, NRC Project Manager

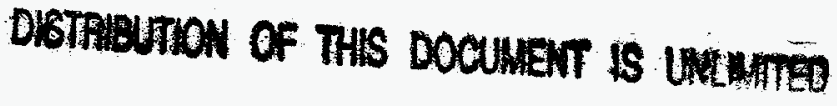

Prepared for

Division of Regulatory Applications

Office of Nuclear Regulatory Research

U.S. Nuclear Regulatory Commission

Washington, DC 20555-0001

NRC Job Code W6761

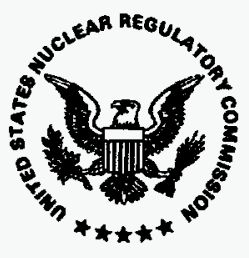




\section{DISCLAIMER}

This report was prepared as an account of work sponsored by an agency of the United States Government. Neither the United States Government nor any agency thereof, nor any of their employees, make any warranty, express or implied, or assumes any legal liability or responsibility for the accuracy, completeness, or usefulness of any information, apparatus, product, or process disclosed, or represents that its use would not infiringe privately owned rights. Reference herein to any specific commercial product, process, or service by trade name, trademark, manufacturer, or otherwise does not necessarily constitute or imply its endorsement, recommendation, or favoring by the United States Government or any agency thereof. The views and opinions of authors expressed herein do not necessar. ily state or reflect those of the United States Government or any agency thereof. 


\section{DISCLAIMER}

Portions of this document may be illegible electronic image products. Images are produced from the best available original document. 


\begin{abstract}
This report describes considerations for the application of the electronic dosimeter (ED)as a measurement device for the dose of record (primary dosimetry). EDs are widely used for secondary dosimetry and advances in their reliability and capabilities have resulted in interest in their use to meet the needs of both primary and secondary dosimetry. However, the ED is an active device and more complex than the thermoluminescent and film dosimeters now in use for primary dosimetry. The user must evaluate the ED in terms of reliability, serviceability and radiations detected for its intended application(s). Available EDs should meet the primary dosimetry needs of many users.

dosimetry the user must establish methods of controlling the performance of the ED in order to ensure long term reliability of the measurements. The user must also develop the methods needed to ensure their proper use as a primary dosimeter. Regulatory groups may also want to develop methods to ensure adequate performance of the ED for dose of record applications. The purpose of this report is to provide an overview of considerations in the use of the ED for primary dosimetry. Considerations include recognizing current limitations, type testing of EDs, testing by the user, approval performance testing, calibration, and procedures to integrate the dosimeter into the users program.
\end{abstract} If the decision is made to use an ED for primary 



\section{CONTENTS}

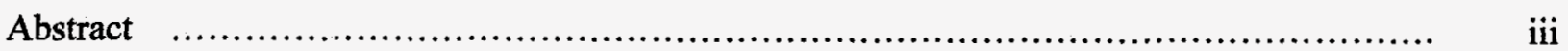

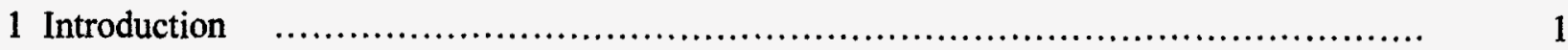

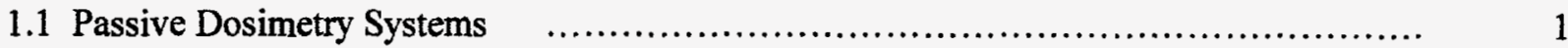

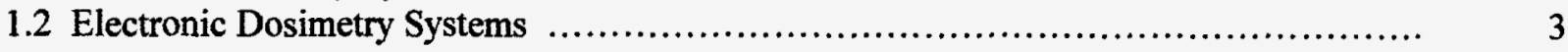

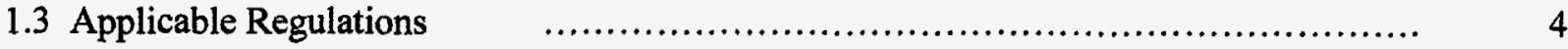

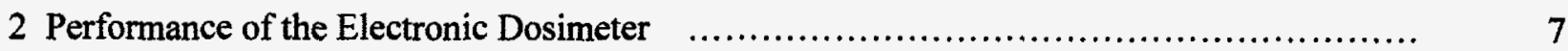

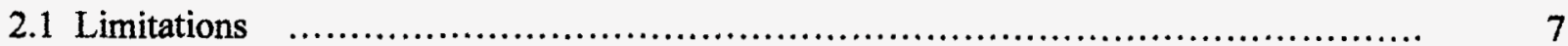

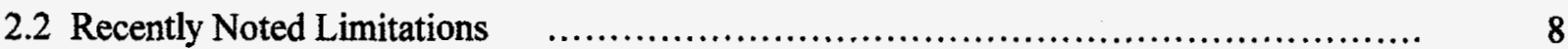

2.3 The Users Environment $\quad$................................................... 11

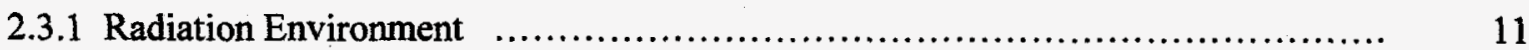

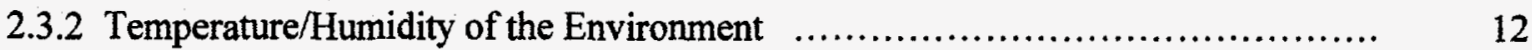

2.3.3 Shock/Vibration $\quad$.................................................... $\quad 12$

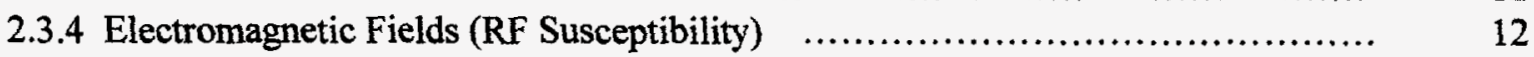

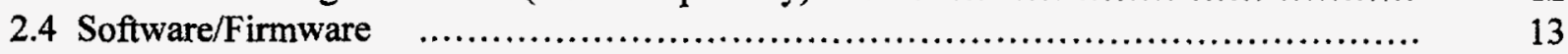

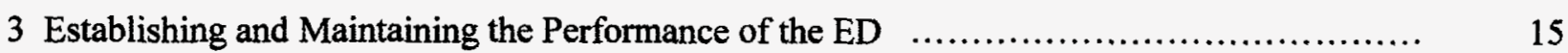

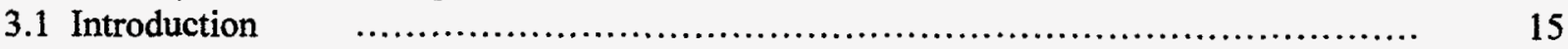

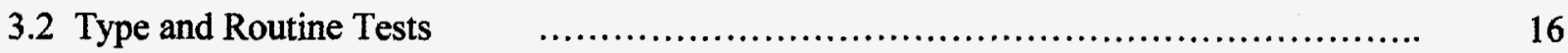

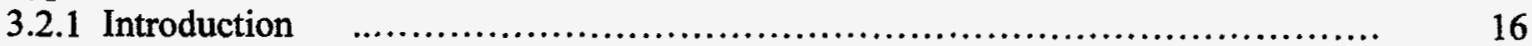

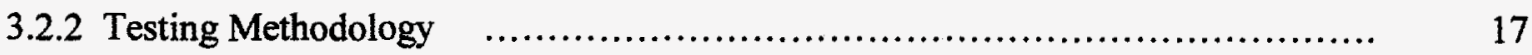

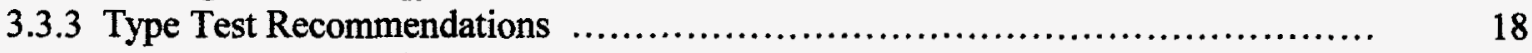

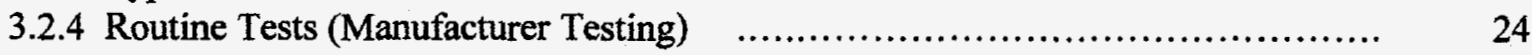

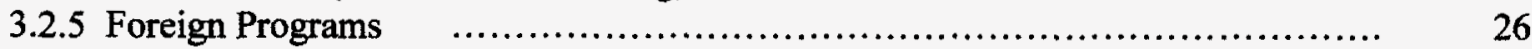

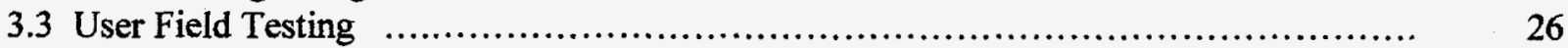

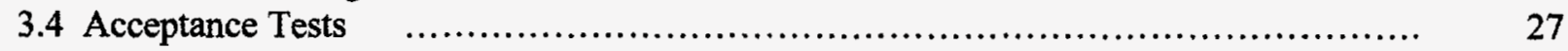

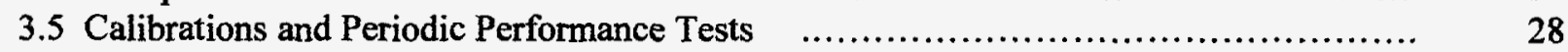

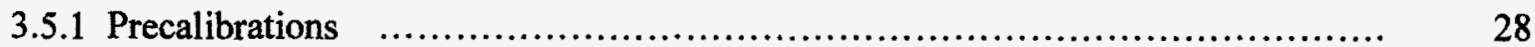

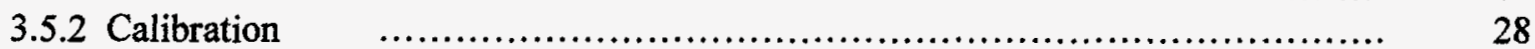

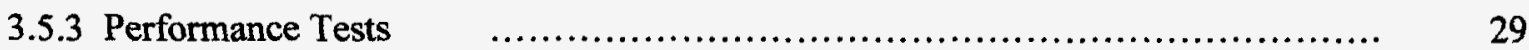

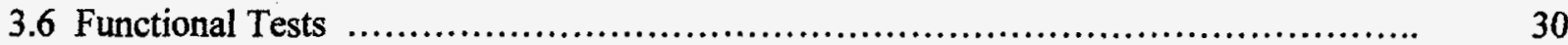

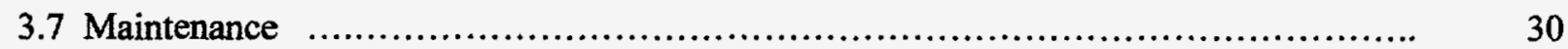

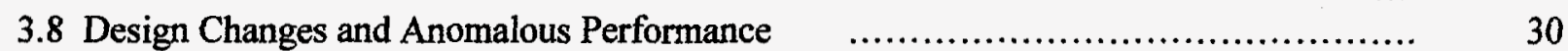

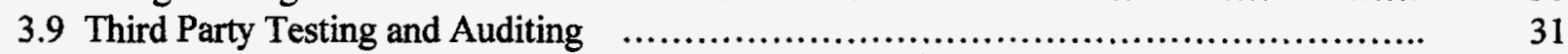

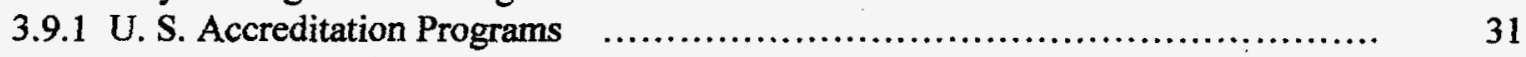

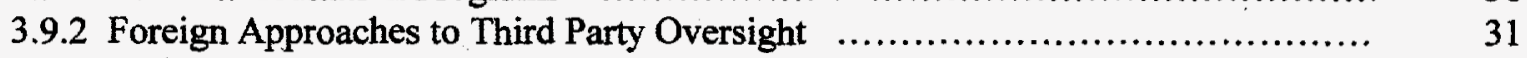

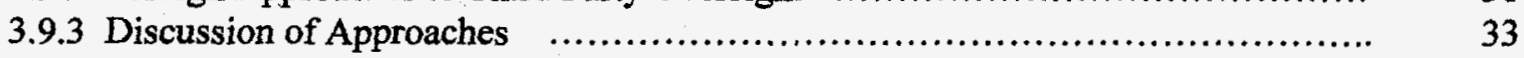

3.10 User Responsibilities ........................................................ 34

3.10.1 Identification of Limitations............................................... 34

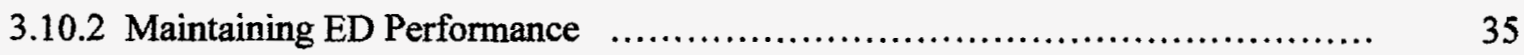

3.10 .3 Records System......................................................... 35

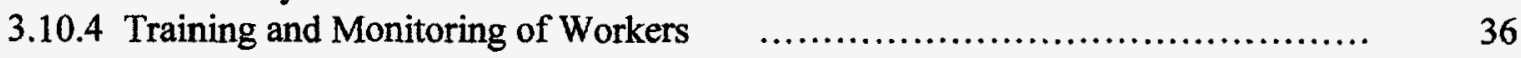




\section{CONTENTS (continued)}

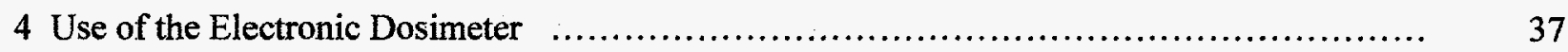

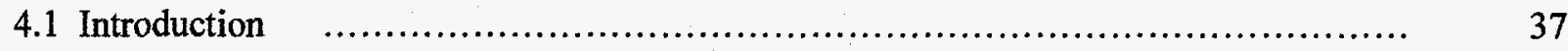

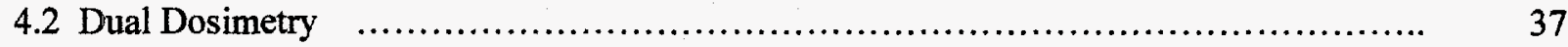

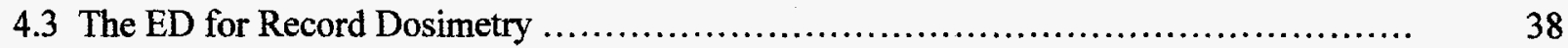

5 Conclusions and Recommendations................................................. 41

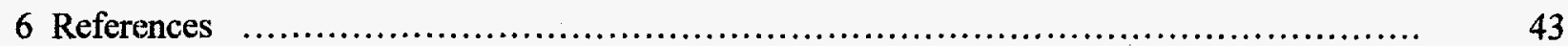

\section{Appendices}

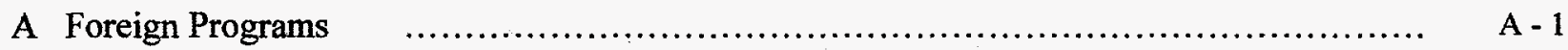

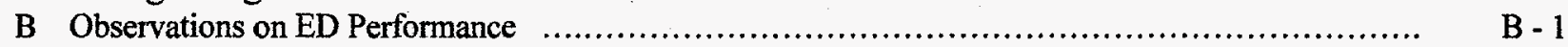

Figures

1 Relationship of the performance control activities for electronic dosimeters.

2 Illustration of the flow of processed dosimeters showing that their readout depends on a common process.

3 Illustration of the flow of the electronic dosimeter showing they are not dependent on a common processing stage.

\section{Tables}

1 General Characteristics and requirements for electronic dosimeters from four standards.

2 Requirements for tests performed with variation of influence quantities from four standards. ..........

3 Procedures for performance evaluation 


\section{FOREWORD}

This report discusses the use of Electronic Dosimeters (EDs) for primary or dose-of-record dosimetry in place of the passive dosimeters (i.e. film or TLD) that are used extensively for this purpose at the present time. EDs have been used for many years as secondary dosimeters for radiation control, because of their ability to supply incremental readings of high doses and high dose rates to the user and to supervisory health physics personnel using telemetry and video monitoring. Now that EDs are more sophisticated and reliable, licensees are considering their use as primary dosimeters, in lieu of film or TLDs.

The work described in this report was performed under contract with Swinth Associates of Richland, WA and is the second report published by the NRC on the subject of ED use in the workplace. NUREG/CR-6354, "Performance Testing of Electronic Personal Dosimeters," was published in August 1995. The purpose of the present report is to provide an overview of practical considerations regarding the use of EDs as primary dosimeters. The report addresses the need to establish conditions and controls for the performance, use, and long term reliabililty of EDs prior to their use.

Evaluation of the conditions under which specific Eds can be used effectively needs to be investigated prior to use. The user must establish methods for controlling the performance and for ensuring the long term reliability of the particular ED being used under the conditions of use and for the radiation in use. Re-examination of the methods is in order whenever radiations or conditions of use are changed.

This document, NUREG/CR-6581, is being published for information only, as part of an ongoing program to keep users appraised of the current status of electronic dosimetry in the US and internationally. The results, approaches, and methods described in this report are provided for information only. Publication of this report does not necessarily constitiute NRC approval of, or agreement with, the information contained herein.

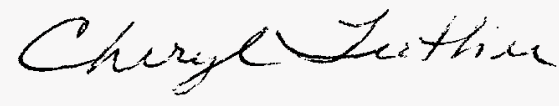

Cheryl A. Trottier, Chief

Radiation Protection and Health

Effects Branch

Division of Regulatory Applications

Office of Nuclear Regulatory Research 


\section{Introduction}

The potential advantages of electronic dosimeters (EDs) have long been recognized (Brown 1966; Erickson 1969, 1970). Historically, the major interest in the ED has been in their potential as secondary dosimetry for alarming and warning the radiation worker of high doses or dose rates. In radiation protection, incremental control of worker exposures is important to ensure that periodic dose limits are not exceeded. Such devices also allow the worker to track his/her radiation exposure and identify work conditions that will lower the radiation exposure (Delacroix, et al. 1995). Introduction of EDs with telemetry along with video monitoring allow the health physics technician to remotely monitor the work thus reducing the collective dose. The ED has become firmly entrenched as the preferred method of secondary dosimetry. Remote monitoring, preset alarms, and electronic data transfer are features that are not offered by other secondary dosimetry systems.

With recent improvements in electronics, the size of EDs has decreased while their capability and reliability have increased. The ED offers monitoring capabilities that are now considered essential in many work environments. With this increase in reliability, the ED is being considered for primary dosimetry in place of the commonly used film badges and thermoluminescent dosimeters. This move could eliminate the cost of maintaining two dosimetry systems. Although they are well established as secondary or supplemental dosimeters, in general their reliability and performance fall short of present primary dosimeters. However, consideration of EDs as primary dosimeters is currently in an evolutionary phase. Improvements in performance and capability are rapid. One recent advance (Wernli 1996) promises a unit that can be used as a conventional dosimeter or linked to an electronics package permitting operation as an
ED. Another advance promises non-contact two way transfer of data with the ED (Lopez 1997) while substantially reducing the package size. At the same time deficiencies in existing products are being identified and eliminated. For example, software problems have been identified and eliminated and the radio-frequency susceptibility of many units has been reduced. Advances are also being made in electronic dosimeters for neutron radiation (Barthe et al. 1997) (Also see Appendix A.3). Personal dosimetry is clearly entering a new phase (Hirning 1995) with the electronic dosimeter destined to play a key role.

The purpose of this report is to highlight the limitations of electronic dosimeters, particularly for their consideration for primary dosimetry, to recommend criteria from specific standards that will ensure the reliability of the ED, and to review and recommend both third party and user methods of ensuring the performance of electronic dosimeters. The report also reviews methods of dosimetry and recommended areas in which the ED may be useful for primary dosimetry despite the limitations at the present stage of development. This report is not intended to detail the performance of the many models of EDs available. Although several deficiencies exist, particularly when considered for primary dosimetry, this report focuses on some models promoted for or appearing to have the capability for use in primary dosimetry.

\subsection{Passive Dosimetry Systems}

Most primary dosimetry systems presently in use are discriminating systems using several detection elements with various filters to permit evaluation of deep and shallow doses, and neutron doses. The systems have evolved into highly reliable methods of recording worker doses. It is 
valuable to examine the overall performance of such systems to provide a baseline for the ED.

The factors affecting the performance of primary dosimeters (Swinth 1988, ANSI 1993b) include temperature, humidity, radiation energy, radiation direction, radiation geometry, fading, remanence, position on the body, contamination, shock/ vibration, calibration accuracy, reader reproducibility, dosimeter linearity, exposure to visible or ultraviolet light, mixed field response (algorithm accuracy), unwanted radiation response, variation in sensor response, and reading errors. Fading can be an important factor (Doremus and Higgins 1994) and algorithms may be used for correction. Similarly, variations in sensor response can be adjusted by calibration or sensor (chip) selection. Dosimeters may require periodic recalibration of chip sensitivity factors to maintain their performance (Grogan et al. 1990). The major factors affecting dosimeters are well understood (Marshall et al. 1994) and may be adequately controlled by design or procedural controls.

The processor is a major participant in the quality or reliability of data obtained from the dosimeter. Serious problems with consistency of primary dosimeter performance led to development of the dosimetry processor accreditation program (Swinth 1988), which is operated by the National Voluntary Laboratory Accreditation Program (NVLAP), using criteria established through technical committees operating under the auspices of ANSI. Its technical recommendations are documented in Personnel Dosimetry Performance-Criteria for Testing, ANSI N13.11 (ANSI 1993). Most processors are successful at meeting the criteria established in ANSI N13.11. The passing percentage in the test categories varies from $93 \%$ to $100 \%$ with the average of the absolute bias plus the standard deviation running from 0.09 to 0.17 (passing $=0.50$ with the exception of the accident categories) (Martin 1994). These test results do not represent the overall accuracy of the dosimetry system since the performance test variables are limited to radiation type (including mixtures) and dose rate. A one time test is performed for angular dependence (tolerance limit $=0.5$ ) which is not repeated unless the dosimeter design is changed.

Other methods of dosimeter performance assurance or control are employed on a national scale, such as type testing supplemented by blind tests in Germany (Bohm and Ambrosi 1990). Such testing examines all variables and the system in Germany is evolving to one based on total uncertainty (See Appendix A.6). Another method of auditing vendor quality is submission of audit dosimeters by the user (spiked and background dosimeters).

The failure rate (anomalous readings, dosimeter damage, etc.) of passive dosimeters is on the order of $0.1 \%$. Catastrophic failures from the processors' standpoint would include chemical contamination (Heinzelmann and Schumacher 1984), processing failure (reader malfunction, film processing error), and damage. Hydrogen sulfide at a few ppm is one common chemical that will cause anomalous readings. The redistribution of the phosphor particles in some designs will also lead to anomalous readings of the dosimeter. In most cases, such anomalies may be detected by review of the glow curve; however, this does not permit restoration of the readings, and estimates for the dose of record will be required. Such estimates (reinvestigations) are performed as required and utilize readings from the other chips, work area dose rates, co-worker doses, etc. These estimates are permitted under 10CFR20.1201(c) (10CFR20 1991). Failure to return the dosimeter is a failure for any dosimetry system.

Obtaining detailed information on the failure rate of dosimeters is difficult since it is not normally reported. However, a German processor who processes in excess of one million film dosimeters per year indicated that in 1996 about $3 \%$ of the badges were not returned and that 
$0.39 \%$ of the badges could not be read due to damage in the field ${ }^{1}$. The service did not experience any loss of data due to processing errors. In discussions with a U.S. utility, they indicated a loss of 2 badges (about $0.02 \%$ ) in one year and they experience a reinvestigation rate of about $0.15 \%$. The reinvestigation rate is the rate at which the numbers appear to be "flyers" and require an analysis to establish a number for the dose of record. This correlates with other statements that the rate of misreads is on the order of $0.1 \%$ for TLDs. It has also been noted that administrative control is important in reducing the rate of lost dosimeters. In another instance a rework volume of $2 \%$ was noted due to false positive beta doses (Whitener 1996). Another investigator reported a false positive rate of approximately $10 \%$ for shallow dose (Lewandowski 1996). The facility did not have a source to cause radiation exposures yet obtained readings of 100 to 400 mrem for the shallow dose. It was felt that the false positives were due to ambient light reaching the shallow dose chip; however, investigations are ongoing.

\subsection{Electronic Dosimetry Systems}

Limited information is available on the overall performance of electronic dosimetry systems. In one case involving 60,000 entrees over a three month period (See Appendix A.1) the failure rate was $0.19 \%$. Over half of the events were blank displays or low battery indications; the next highest fault was spurious dose accumulations and there was only one event ascribed to radio frequency interference. In most of these cases the dose data could be recovered from the EEPROM memory of the dosimeter. Siemens has noted a $0.025 \%$ data loss rate for radiological control area entries. These rates compare favorably with the reinvestigation rate for passive dosimeters; however one must remember that there are a lot more readings (entrees) per worker than for a

\footnotetext{
${ }^{1}$ Ritzenhoff, K. H., 1997. Personal Communication
}

passive dosimeter. Thus the probability of a reinvestigation for an individual worker is higher although the associated incremental dose should be much lower resulting in a smaller impact of any data loss or errors. In Japan, electronic dosimeters are under active development as the primary dosimeter and the failure rate for one model is quoted at $0.004 \%$ (Suzuki 1996). The NRPB in Great Britain is currently using the electronic dosimeter for dose of record (approval granted August, 1994) and are generally pleased with the performance of the system ${ }^{2}$. NRPB does use other dosimeters in areas where the electronic dosimeter is not suitable.

There have been several comparisons of passive dosimeters and electronic dosimeters worn for the same period of time. In one reported study the analysis showed a mean difference of $17 \mu \mathrm{Sv}$ (1.7mrem) with a standard deviation of $82 \mu \mathrm{Sv}$ (8.2mrem) (Van Cauteren and Bricoult, 1996). The intercomparisons can be difficult to interpret since the minimum level for a typical TLD system is about $10 \mathrm{mrem}$ while it is about $0.1 \mathrm{mrem}$ for the ED. Thus at low exposure rates the ED may show an exposure of a few mrem over a reporting period while the TLD shows no exposure. Alternatively at a low but constant exposure rate the ED may show no exposure and the TLD may show 10-15 mrem. This is the case when the ED is used communally and is reset everytime one enters or leaves the radiation area.

Limited testing of the electronic dosimeter against NVLAP tests has been performed (Martin 1996a). Most of the testing has been in Categories IV and IX where the mean values for $\mathrm{B}+\mathrm{S}$ have been approximately 0.11 and 0.16 respectively. In an independent evaluation of the Siemens ED by Calvert Cliffs Nuclear Plant (Paulhardt 1996) using the ANSI N13.11 performance criteria, it was shown that the ED could perform within the criteria with the exception of the shallow dose for the $\mathrm{M} 30$ radiation quality ( $20 \mathrm{keV}$ average)in

\footnotetext{
${ }^{2}$ Marshall, T., 1997. Personal Communication
} 
mixtures and alone and for neutrons which it is not expected to measure. Generally the performance was within 0.25 for $\mathrm{B}+\mathrm{S}$ including angular testing. In a comparable study, performance tests at the Pacific Northwest Laboratory (Piper et al. 1993) on the Siemens ED demonstrated excellent performance against ANSI N13.11-1983 and DOE/EH-0027 test categories with the exception of the low-energy x-ray categories M30 (20 keV average) and $\mathrm{K} 17$ (17 keV K-fluorescence technique). The unit passed the beta test categories, but failed in neutron categories as one would expect. The test data indicated that the unit would pass the testing criteria to individual as well as mixed beta-photon fields over its stated range of sensitivity.

\subsection{Applicable Regulations}

Nuclear Regulatory Commission regulations pertaining to the monitoring of individual workers for exposure to external radiation are found in 10CFR20 (10CFR20 1991); however, specific requirements for specific categories of work can be found in other regulations. The licensee is required to supply and require the use of individual monitoring devices by adult workers likely to receive in excess of $10 \%$ of the dose limits $(20.1502(a)(1))$ or individuals entering a high or very high radiation area (20.1502(a)(3)). The applicable dose limits are a total effective dose equivalent of $5 \mathrm{rem} / \mathrm{y}(20.1201$ (a)(1)(i)), an eye dose equivalent of $15 \mathrm{rem} / \mathrm{y}(20.1201(\mathrm{a})(2)(\mathrm{i}))$ or a shallow dose equivalent of $50 \mathrm{rem} / \mathrm{y}$ to the skin or any extremity (20.1201(a)(2)(ii)). Doses to workers are also required to be kept as low as reasonably achievable (ALARA) (20.1101(b)). Thus a licensee is not required to monitor workers unless the annual effective dose is likely to exceed $500 \mathrm{mrem}$, the eye dose likely to exceed $1.5 \mathrm{rem}$ or the dose to the extremities or skin is likely to exceed 5 rem.
When an individual monitoring device is used certain requirements apply to the device. Quoting directly from the regulations $(20.1501(\mathrm{c}),(\mathrm{c})(1)$, (c)(2)):

"All personnel dosimeters (except for direct and indirect reading pocket ionization chambers and those dosimeters used to measure the dose to the extremities) that require processing to determine the radiation dose and that are used by the licensees to comply with paragraph 20.1201, with other applicable provisions of this chapter, or with conditions specified in a license must be processed and evaluated by a dosimetry processor-

(1) Holding current personnel dosimetry accreditation from the National Voluntary Laboratory Accreditation Program (NVLAP) of the National Institutes of Standards and Technology; and

(2) Approved in this accreditation process for the type of radiation or radiations included in the NVLAP program that most closely approximate the type of radiation or radiations for which the individual wearing the dosimeter is monitored."

Further:

"Dosimetry processor means an individual or an organization that processes and evaluates individual monitoring equipment in order to determine the radiation dose delivered to the equipment."

As noted by others the electronic dosimeter (in a manner similar to the direct and indirect reading pocket ionization chambers) does not require processing to determine the radiation dose. Thus the requirements of personnel dosimetry accreditation are not currently applicable to the ED. Although the microprocessor in the typical ED does manipulate and process the signals derived from the detector(s), this is a separate issue from the processing of the device, the ED. 
Other regulations pertain to the use of dosimetry. Specifically 10CFR34.47(a), ${ }^{3}$ 10CFR36.55(a), ${ }^{4}$ and 10CFR39.65(a) ${ }^{5}$ require the use of individual film or TLD dosimeters. Only 10CFR34 mentions the use of an electronic dosimeter (EPD) in place of a direct reading ion chamber (DRD). An alarming ratemeter is required in addition to the DRD or EPD.

Although the NRC has no official position on the use of the ED for primary dosimetry, memoranda have been provided by NRC offices which are positive with regard to the use of the ED as a replacement for conventional dosimetry techniques. Sections of a letter by Frederick $\mathrm{Combs}^{6}$ answering whether the NRC will accept the electronic dosimeter as a suitable replacement for film and TLD, whether acceptance is contingent on certain procedures, and if the loss of third party overview raises a question on security of data are quoted below:

"The answer is in the affirmative: there is nothing in the regulations to preclude such use, with the exception of regulations that explicitly require the use of film or TLD,..." [see above]

"Acceptance is not contingent on any specific procedures to be implemented by the licensee. The only requirement for use of the EPDs (Electronic Personal Dosimeters) is that the licensee follow procedures and good practices normally observed when using radiation detection instruments to obtain important, safety-related measurements, such as proper maintenance and

\footnotetext{
${ }^{3}$ 10CFR34, "Licenses for Industrial Radiography and Radiation Safety Requirements for Industrial Radiographic Operations."

${ }^{4}$ 10CFR36, "Licenses and Safety Requirements for Irradiators."

${ }^{5}$ 10CFR39, "Licenses and Radiation Safety Requirements for Well Logging."

${ }^{6}$ Letter from F.C. Combs, Chief of the Operations Branch, Division of Industrial and Medical Nuclear Safety, Office of Nuclear Materials Safety and Safeguards of the NRC to NC Systems, Inc. dated November 9, 1993.
}

calibration, awareness of the instrument's limitations, training in its proper use, a good quality assurance program, accurate and secure data collection and storage, and so on. Licensees who choose to use EPDs must be prepared to implement such a program at their facilities."

"Although this possibility has always existed, we feel that it is the licensee's responsibility to ensure the security of the data. The methods used to attain the desired level of security would be reviewed within the context of NRC's licensing and inspection activities.... No serious problems pertaining to data security have been encountered to date."

"......the NRC is aware of the potential problems involved in the use of EPDs as dosimeters of record. However, it was concluded that EPDs could serve this purpose if the normal precautions mentioned above are observed."

Thus it appears that for most licensees, the use of NVLAP accredited dosimeters is not required and that the acceptance of the EPD simply requires a well thought out and implemented program to ensure the appropriate reliability and security of data. 



\section{Performance of the Electronic Dosimeter}

The overall performance of the electronic dosimeter was covered in section 1.2 of the introduction. It is clear that in a purely performance test environment the ED can perform adequately in selected test categories and can meet and occasionally exceed the performance of passive dosimeters. Since this is not a mature technology additional improvements can be expected in the future. However, the ED does have specific limitations that become apparent in the field and when tested against specific influence quantities. Some of these limitations are noted below along with definition of the typical environment where the performance is to be evaluated. Issues related to software are discussed separately.

\subsection{Limitations}

In the earlier report on electronic dosimetry (Swinth, et al. 1995) several limitations of the electronic dosimeter were highlighted and discussed as well as some of the concerns over current testing. This information was derived from a user survey conducted by NEI and published or unpublished studies. Several of these limitations are still important although progress has been made to reduce these limitations and improve overall performance. These limitations are highlighted below:

- Most EDs have a poor energy response below approximately $70 \mathrm{keV}$.

- Environmental conditions, such as electromagnetic radiations and moisture, can affect ED performance.
- The ED is still evolving. Some inherent defects have been located (e.g., software malfunction) and, in some instances, the quality of delivered units has been unacceptable (e.g., high failure rate).

- Due to the poor low-energy response, the single detector ED will not pass ANSI N13.11 dosimetry performance test criteria (ANSI 1993) for categories using low-energy photons.

- The criteria used in evaluating ED performance vary widely. In addition, the tests are not always objective. For example, in one case, susceptibility was tested by placing the antenna of a transceiver within "one-half inch" of the ED. Radiofrequency field intensity varies rapidly with distance and repeatability or reproducibility of tests requires a field intensity measurement. Transceiver output can also vary with factors such as battery condition or condition of the transceiver.

- Dose conversion factors needed to convert air kerma to deep and shallow dose equivalent are not consistently used for instrument testing or calibration. Ambient dose equivalent and directional dose equivalent should be used for instruments. Personal dose equivalent should be used for dosimeters. Care must be taken to use the appropriate conversion factors for EDs.

In recent years several operational problems have been identified and corrected. These have included software problems; one example is given by Hirning et al. (1994). Radio frequency 
susceptibility is a limitation and although redesign by manufacturers has improved the immunity of the ED, some limitations still exist.

Manufacturers have improved drop resistance and there have been instances where EDs have been dropped over 50 feet and still remained operational. Anomalous readings caused by shock to the case (tapping, bumping, etc.) have been corrected by a combination of shock mounting of internal components and circuitry. In recognition of this problem a test for "microphonics" was added to a draft IEC standard (see Table 2).

\subsection{Recently Noted Limitations}

A recently published article (Lantz 1996) provides a list of limitations (dosimeter weaknesses) of the electronic dosimeter. Unfortunately, the items are not associated with a specific user or ED which makes a specific response difficult. Many of the concerns are limited to one model and may be experienced by a few user and not by others. The performance of some EDs may not be acceptable for secondary dosimetry much less for primary dosimetry consideration. Manufacturers contacted regarding the article have stated that: "We don't have those problems." However, they have not been willing to provide a point by point reply. Following are comments on some of the key issues noted in the article plus some other key concerns that have been voiced. A listing of additional concerns and with a general observation are noted in Appendix B. Clearly additional efforts are needed to fully resolve such issues and increase confidence in the reliability of the ED.

\section{- Variable PIN diode energy response}

Examining type testing data for an ED using a single PIN diode showed a ${ }^{137} \mathrm{Cs}$ normalized response of $1.116 \pm 0.061$ for $65 \mathrm{keV}$ xrays. The range was $+8.9 \%$ to $-6 \%$. Examination of data for a series of $31 \mathrm{EDs}$ exposed to $\mathrm{M} 100 \mathrm{x}$ rays (average energy $51 \mathrm{keV}$ ) showed a value of $1.028 \pm 0.0165$ (the range was $+4.9 \%$ to $-2.7 \%$ ) compared to the conventional true value for the penetrating dose and $1.131 \pm 0.033$ (the range was $+9.5 \%$ to $-4.1 \%$ ) for the shallow dose.

Normalizing these values to ${ }^{137} \mathrm{Cs}$ may increase these variations slightly. Variation in energy response was noted by Swinth et al. (1995) for units based on energy compensated GeigerMueller detectors. One must expect a variation in the energy response between units of the same model and this demonstrates the need to test a series of units. However. based on the data available, the consistency of performance at low energies for these models appears to be satisfactory.

\section{- Poor angular response of electronic dosimeters}

The response of EDs is not isotropic and should not be isotropic as suggested by Lantz. The expected variation for the deep dose equivalent can be found in ANSI N13.11 (ANSI 1993). Concern has been expressed over serious errors in dosimetry for sources located underfoot, overhead, or to the sides of the worker caused by poor angular response. In terms of effective dose equivalent (Reece 1996), a dosimeter with isotropic response will overestimate the effective dose equivalent by a factor of 2-5 for these situations. Measurements (Piper and Scherpelz 1997) with three models of electronic dosimeters showed an anisotropic response that did not always decrease with increasing angle. In some cases the ED tracked the effective dose fairly well. The deep dose equivalent drops quickly at angles beyond $60^{\circ}$ (the common limit on angular testing) and most EDs do not model the response correctly; their response is too isotropic.

\footnotetext{
${ }^{7}$ Paulhardt, W.K., 1997. Personal Communication
} 
Examination of type test data for an ED using a single silicon diode shows that the response is within $\pm 20 \%$ of the $\mathrm{Hp}(10)$ value for angles out to $60^{\circ}$ for both high ( $\left.660 \mathrm{keV}\right)$ and low ( $65 \mathrm{keV}$ xrays) energy photons. The dosimeters meet the requirements of draft ISO $1526 ; \pm 20 \%$ for 660 $\mathrm{keV}$ and $\pm 50 \%$ for $59.6 \mathrm{keV}$. It should be noted that the tolerance limit over the same range for Category IX (angular response) in ANSI N13.11 is 0.50 . Angular response for the ED is affected by the battery at higher angles. However, based on the studies of Reece (1996) and Piper and Scherpelz (1997) this may turn out to be an advantage if the battery is properly placed.

EDs will meet (in most cases) guidance provided in type testing standards for angular response which is as severe as the requirements for passive dosimeters (ANSI 1993). Without additional guidance on effective dose equivalent or requirements for $\mathrm{Hp}(10)$ at extreme angles, it is difficult to further evaluate angular response or to establish additional requirements for angular response. This issue affects both the present passive dosimeters and the ED.

One critical issue is response of the ED from the back. One model has a battery covering most of the back which will invalidate measurements if the ED is worn backwards. As noted elsewhere, German regulations require labeling of all such EDs to clearly indicate which side must be placed next to the body.

\section{- The inherent performance of the electronic components limits the lifetime of the ED (implying a costly method of dosimetry).}

Two factors may limit the inherent "electronic" lifetime of the ED. First, EDs use CMOS circuitry to reduce power consumption and CMOS circuitry has a higher susceptibility to radiation damage than other types of semiconductors. The effects of damage can be expected at approximately 20,000R; such exposures are highly unlikely. The same type of circuitry is used in survey instruments and the concern in this case has focused on calibrations where frequent calibrations with testing of the overdose response could lead to significant integrated doses. The second issue is the lifetime of the EEPROM memories which have limited erase/write cycles. However, calculations for one model indicate a lifetime on the order of 13 years. As with all semiconductors the capabilities of the EEPROM are improving with higher capacities (storage of more data) and more read/write cycle (lifetime) capability (an order of magnitude improvement). Intrinsic lifetime does not appear to be a serious concern.

- Some EDs have been noted to mechanically fail (i.e., in need of repair or replacement) at a significant rate: up to $30 \%$ per year.

One manufacturer notes that factory returns on a recent large order were $0.15 \%$ other data have indicated a failure rate of $4.7 \%$ during a trial period with 1000 units from a different manufacturer. Design and reliability testing tools are available to the manufacturers. High failure rates will result in loss of market share. The market place will take care of this problem.

- The data loss rate for electronic dosimeters is higher than for passive dosimeters.

Data indicates that failure rate based on number of readings is comparable to or lower than that for passive dosimeters (see section 1.3). However, the frequency of reading the units is much higher. Since data is written to a nonvolatile memory the actual loss of data is low and when data is lost due to the short period covered it is easy to reconstruct activities and use dosimetry data from coworkers.

- Magnetic fields have been known to turn some EDs off. 
This is an issue that needs to be resolved by testing, dosimeter shielding and worker training.

- ED internal electronic checks are questionable.

Although NUREG/CR-6354 recommended a reduced frequency of source checking if the ED possessed a background count checking capability, this must be adjusted if experience indicates that the internal check is not adequate.

- EDs are spiking or scrolling to high and low doses.

- High ED dose rates are occurring throughout the industry.

Anomalous readings should be identified throughout the industry and resolved. If these are due to radiofrequency interference on older models this may be a moot point since, hopefully, such EDs will not be used for the dose of record.

- Unusual performance test failures have been discovered without a determination of the cause.

Such problems should be identified and resolved with the manufacturer and if not resolved these models should not be used. If the problem is associated with a particular dosimeter it should be removed from service.

- Simple occurrences such as keys rattling in front of the dosimeters, pen tapping on the case, dosimeters being dropped or squeezed, RFI, magnets and microwaves have disrupted ED measurements.

All of these issues are addressed by type tests, including the shocks to the case (microphonics). EDs that perform satisfactorily on these tests should not experience these problems.
- Increasing the chirp rate on one type of ED caused them to underrespond by $75 \%$

This issue should be resolved and such performance is not acceptable for dose of record.

- Failures of the ED control software at the $R C A$ entrance have been found.

Such issues with the software must be identified and resolved.

- PIN diode detectors may be angular dependent.

All dosimeters should have an angular dependence to correctly measure deep dose equivalent or effective dose equivalent. If the response from the rear is substantially lower, the dosimeters should be labeled to ensure that they are worn correctly.

- Although EDs are calibrated to equate to TLDs and pocket dosimeters in laboratory irradiations, the majority of EDs read lower in field exposures.

Facilities should not tailor the calibration of the ED to match another device, particularly if they are to be used for the dose of record. The 4$8 \%$ difference noted is well within the permitted uncertainties published in ICRP 35 (ICRP 1982). The response in Xe-133 environments needs more investigation, but with the demonstrated agreement among dosimeters does not appear to be a major problem.

- Some EDs can have a significant dose rate dependence, depending on the type of detector, circuitry, and processing algorithm.

The ED does have limitations at high dose rate as demonstrated in type tests. At such high dose rates the ED should not be used as the primary dosimeter. 


\subsection{The Users Environment}

One of the first tasks in selecting (or testing) a dosimeter is defining the environment in which it will be used. This involves identifying and determing the characteristics of all environments that may influence the response of the dosimeter. Once identified these characteristics can be used to evaluate the appropriateness of each model by evaluating the specifications or type test data when it is available. Many of these influence quantities are defined in type test standards thus defining a performance envelope for the tested device, but the range of values may not be appropriate to the intended use. When the range of the influence variables experienced by the user extends beyond specifications in the standards or the manufacturer's specifications, the user must determine if the use can be kept within specifications by administrative controls or if the excursions beyond the specified envelope are acceptable due to a) low frequency of occurrence or b) low impact on the measurements. An alternative is to perform additional testing to determine the impact of the influence variables and/or request additional development of the device. In the following sections some of the influence variables and typical ranges for these influence variables in the nuclear power industry are outlined. Many of these are adapted from the surveys and research performed for NUREG/CR6354 (Swinth, et al. 1995).

\subsubsection{Radiation Environment}

Key parameters of the radiation environment are the radiation type, the radiation energies present and the source distribution (angular distribution). In terms of radiation type most users feel that the primary radiation of concern is photon radiation. Neutron and beta radiations could be accommodated by other dosimeters. Respondents to a survey (Swinth, et al. 1995) indicated that in the case of beta radiations, workplace surveys could be used to show that beta doses are inconsequential and adequately controlled by control of the penetrating dose. In terms of angular response the angular response is defined by standards such as ANSI N13.11(ANSI 1993) as a function of energy and defining the energy range will define the required angular response.

Spectroscopy measurements at nuclear power plants (Roberson et al. 1984) have shown that the typical "plant mix" of radioisotopes is a mixture of primarily ${ }^{137} \mathrm{Cs}$ and ${ }^{60} \mathrm{Co}$. At reactors studied by Roberson et al. (1984), most have radiation fields of nearly all medium-energy photons, due to radioactive decay of cobalt and/or cesium isotopes, or a combination of medium-energy photons with a scatter continuum. Low-energy photons at commercial nuclear reactors occur because of scattering in shielding material. Note that "low-energy," in this context, refers to photons with energies $<200 \mathrm{keV}$, "mediumenergy" refers to $200-\mathrm{keV}$ to $3-\mathrm{MeV}$ photons, and "high-energy" to photons with energies $>3 \mathrm{MeV}$. Sorber et al. (1988) performed a study showing a lack of low-energy photons in selected nuclear power plants, thus supporting the study of Roberson et al. (1984). The only significant lowenergy photon fraction was in the vicinity of the waste-gas decay tank (Xe-133); an area that is not normally occupied by workers. Sorber et al. (1988) concluded by stating that, "Therefore, it is not necessary, under normal operating conditions, to calibrate or otherwise test the normal personnel dosimetry system for photon energies below 70 $\mathrm{keV}$. The Japanese characterized the radiation in their light water reactors (Suzuki 1996) and found that with the exception of the off-gas valve room there was little contribution to the dose below 100 $\mathrm{keV}$. Further, analysis of 70,854 film badges from a period of 26 months (Suzuki 1996) showed no contribution from neutrons or betas. Also as noted by Lantz (1996), "only a small component of worker doses are due to photons below 100 keV." 
Based on this information the primary concern in most nuclear plants is photons in the energy range from about $100-1250 \mathrm{keV}$ with high energy photons $(6 \mathrm{MeV})$ in some plants. Thus it is reasonable to use photon dosimeters covering an energy range of approximately $60 \mathrm{keV}-1250 \mathrm{keV}$ plus $6 \mathrm{MeV}$ for routine dosimetry applications. However, it is important to note that if there is a breach of containment and fission products become a concern, beta and low energy photons will be an exposure concern. Data also shows that EDs underrespond at dose rates above approximately $100 \mathrm{mrem} / \mathrm{h}$. Thus one would need to consider supplemental dosimetry for emergencies, for operations requiring breach of containment, and for areas with a neutron component to the dose.

\subsubsection{Temperature/Humidity of the Environment}

The temperature and humidity environment in a nuclear plant can vary considerably, but temperatures below freezing will be rare and a typical upper limit for temperature can be taken from survey results, $55^{\circ} \mathrm{C}$ (Swinth et al. 1995). Thus temperature testing should extend over a range of $0-55^{\circ} \mathrm{C}$. Based on discussions $E D s$ can be exposed to maximum humidity conditions (located in a pile of sweat soaked coveralls) or exposed to rain. Humidity testing should include both exposure at $95 \% \mathrm{RH}\left(35^{\circ} \mathrm{C}\right)$ and testing with light rain. Extreme moisture conditions such as extended rain and extended humidity conditions should be handled by enclosing the ED in a plastic bag (administrative control).

\subsubsection{Shock/Vibration}

The major concern in this case is dropping of the ED. A minimum test distance would be about $25 \%$ higher than the height at which the ED is normally worn (breast pocket; 1.4 meters). This would be a height of approximately 1.75 meters. Vibration is more a durability issue than a representation of a workplace influence quantity. Testing at $2.0 \mathrm{~g}$ is low. Initial testing for ANSI $\mathrm{N} 42.17$ (ANSI 1989) was performed at $2.5-3.0 \mathrm{~g}$ and the value was reduced due to displacement of a light duty mechanical spring in the meter movement of some portable instruments. This is not an issue with EDs and testing at $3.0 \mathrm{~g}$ is recommended; this is still less than the $5-8 \mathrm{~g}$ recommended for screening of equipment (DON 1979, Kececioglu and Feng-Bin 1995).

\subsubsection{Electromagnetic Fields (RF Susceptibility)}

Over the past 10 years the sources of r.f. interference in the typical workplace have increased dramatically. Increasing use of wireless modems, cellular phones and hand-held transceivers have increased the number of sources of intense radio frequency radiation. In the medical field, r.f. interference has been associated with life threatening situations (Silberberg 1994) and the Center for Devices and Radiological Health (CDRH) considers control of this threat a high priority activity (Witters 1995). International standards consider the field strength in industrial settings to be about $30 \mathrm{~V} / \mathrm{m}$ and an immunity level of $30 \mathrm{~V} / \mathrm{m}$ is considered adequate for many situations. It is noted that for a field strength of $20 \mathrm{~V} / \mathrm{m}$ the separation distance is about $20 \mathrm{~cm}$ for a cellular phone, $50 \mathrm{~cm}$ for a $\mathrm{CB}$ radio, $500 \mathrm{~cm}$ for a patrol car and $3000 \mathrm{~cm}$ for a TV transmitter (Witters 1995). Field strength falls off rapidly with distance from the transceiver, but with many workers equipped with both an electronic dosimeter and a transceiver, the probability of activating a transceiver within $10-30 \mathrm{~cm}$ of an ED is high. At such distances field strengths of greater than $100 \mathrm{~V} / \mathrm{m}$ are not unexpected. It is difficult to measure or calculate r.f. intensities near the source, but an extrapolation based on the dipole equation in Silberberg (1994) suggests an intensity of $100 \mathrm{~V} / \mathrm{m}$ at $10 \mathrm{~cm}$ for the $\mathrm{CB}$ radio example. Studies by Adams, et al. (Adams, et al., 1990 ) on high powered personal transceivers showed maximum field strengths of $82-880 \mathrm{~V} / \mathrm{m}$ for various $5 \mathrm{w}$ hand-held transceivers at $7 \mathrm{~cm}$ distance. At $12 \mathrm{~cm}$ the fields ranged from 180 to 
$425 \mathrm{~V} / \mathrm{m}$. For two $3 \mathrm{w}$ models operating at $823 \mathrm{MHz}$ the maximum intensities were $158 \mathrm{~V} / \mathrm{m}$ and $95 \mathrm{~V} / \mathrm{m}$ at 7 and $12 \mathrm{~cm}$ respectively. The fields were anisoropic, varied with model and frequency and exceeded ANSI (ANSI 1982) safety guides by as much as two orders of magnitude. Testing needs to be done at reasonably high field strengths if it is to assure the user of any degree of r.f. immunity in the tested device. As noted by White(1995), field strengths of $10 \mathrm{~V} / \mathrm{m}$ are not likely to cause problems, but few devices will be immune to field strengths greater than $100 \mathrm{~V} / \mathrm{m}$.

In addition to the radio transceivers in the work place, other sources such as heat sealers, metal detectors, engine ignition systems, welders, central transmitters, etc. may be encountered at some locations in the work area. In one example, the electric field in the vicinity of the eyes of an operator of a plastic welding device (27MHz) was $800 \mathrm{~V} / \mathrm{m}$, but was reduced to $42 \mathrm{~V} / \mathrm{m}$ after shielding (Orsini et al. 1988). It may be necessary to identify and shield such sources or to administratively limit the use of the ED in their vicinity.

Type testing of EDs should be performed with field strengths of $100 \mathrm{~V} / \mathrm{m}$ or greater from $300 \mathrm{kHz}$ to $30 \mathrm{MHz}$ and at $70 \mathrm{~V} / \mathrm{m}$ from 30 to $300 \mathrm{MHz}$ where safety standards recommend a value of about $63 \mathrm{~V} / \mathrm{m}$ (ANSI 1982). It should be noted that safety standards will permit field intensities up to $630 \mathrm{~V} / \mathrm{m}$ at the lower frequencies. For radiated fields above about $300 \mathrm{MHz}$ tests should be at $100 \mathrm{~V} / \mathrm{m}$. In addition the user should take the responsibility for testing of the specific ED he intends to use with the r.f. generating devices in use within his facility.

\subsection{Software/Firmware}

The programs used to control the ED and transfer data from the ED can be particularly troublesome since it is not easy to determine the impact of one programming sequence on other functions of the software. During linearity testing, it was found that with one model of ED it started to record only one-half the delivered dose after repeatedly running the self-test feature. This was investigated by the manufacturer and found to be a specific software design error, which was corrected. The failure occurred randomly (approximately $10 \%$ of trials) and could be corrected by removing the battery and resetting the ED. In another instance the light pulses on the detector used to verify operability of the ED while in the active mode can cause a timing conflict which causes the unit to fail the test and alarm. In about $10 \%$ of the occurrences this can affect the recorded dose. In one example this caused an affect on $0.012 \%$ of the entrees. The test function can be deactivated.

Testing directly for such software problems is difficult. In general the best approach is to submit new software to a testing period during which the users can operate the units in ways the manufacturer does not expect or anticipate. Users should be encouraged to submit the units to unusual operation sequences during field evaluation and document any unusual occurrences.

Testing should extend to the ED reader software to ensure that the data is consistently and accurately transferred, including dose data, alarm settings, identifications, etc. and that the ED is properly activated or deactivated. The software/firmware versions should be properly documented and should be part of the approval process for an ED. All EDs should be labeled with the model number and the version number of the installed software.

Guidance for verifying and validating algorithms used to estimate dose from the detector may be found in standards such as ASME NQA-2 (ASME 1989), the Appendix of ASME NQA-2a (ASME 1990), ANSI/IEEE 1012 - 1986 (ANSI 1986), and ANSI/IEEE Standard 730 (ANSI 
1989). Most of these pertain to the manufacturer

and documentation requirements for his software. 


\section{Establishing and Maintaining the Performance of the ED}

\subsection{Introduction}

In order to ensure the adequate performance of an ED, one must first establish the required performance envelope (set of specifications) for the device, followed by establishment of the requirements and processes needed to maintain performance within the established envelope. The type test, field tests and formal performance tests will establish a documented set of performance specifications for the electronic dosimeter. By design these should be adequate to ensure satisfactory operation under the anticipated set of influence quantities. Once the performance envelope is established the manufacturer and user must take additional steps to ensure that performance remains within the envelope. This involves routine tests and calibrations by the manufacturer, acceptance tests by the user and, following acceptance, a set of functional tests, performance tests, calibrations and maintenance during deployment. Third party auditing may also be included that could include calibration accreditation, dosimeter accreditation, audits and performance tests. Figure 1 illustrates the relationship of these various activities. Definition of some of these activities follows.

\subsubsection{Type tests -}

A test of one or more dosimeters made to a certain design to show that the design meets the specifications of a selected standard.

\subsubsection{Routine tests -}

A test to which each individual dosimeter is subjected during or after manufacture to ascertain whether the dosimeter complies with certain criteria.

\subsubsection{Field tests -}

Evaluations of performance made while in trial use in the field to evaluate the device. Manufacturers would perform such testing to identify limitations that did not surface during laboratory tests. Users would perform such testing during the selection process to identify operational problems or limitations in their specific work environment.

\subsubsection{Acceptance tests -}

Contractual tests carried out on a dosimeter of a particular type before the dosimeters are put into service for the first time. The tests are intended to demonstrate that every dosimeter in a consignment conforms with its specification.

\subsubsection{Approval performance tests -}

Performance tests carried out to demonstrate that the required performance specifications are met. Such tests are compared to recognized requirements and are usually conducted by a third party.

\subsubsection{Routine performance tests -} Tests carried out periodically (routinely) to test the accuracy and precision of the dosimetry system for the measurement of doses at a single energy.

\subsubsection{Functional tests (checks) -}

Tests (often qualitative) to determine that an instrument is operational and capable of performing its intended function. Functional tests may include, for example, battery checks, source response checks, internal electronic tests, simulated radiation counts, and background counts.

\subsubsection{Calibration -}

To adjust or determine or both the response or reading of an electronic dosimeter relative to a series of conventionally true values over the range of the instrument.

\subsubsection{Conventionally true value -}


The best estimate of the true value of a quantity measured using sources or standards traceable to primary standards maintained by the National Institute of Standards and Technology (NIST).

\subsubsection{Source response check (source check) -}

The check of instrument response to a radioactive source (not necessarily calibrated) to determine that the instrument is still functional within an acceptable range.

\subsection{Type Tests and Routine Tests}

\subsubsection{Introduction}

Type tests and routine tests are designed to characterize and maintain the performance of a specific model of instrumentation (ED). This introduction includes a discussion of general aspects of testing and testing philosophy. Type tests are performed on a random sample of representative dosimeters from the routine production. Due to the large number of such dosimeters expected to be in use, the type test should be carried out on a sample of 15 or more dosimeters. Smaller samples may be used on specific tests when the variation in performance is: a) expected to be small, or b) failures, if they occur, are expected to be dramatic. Routine tests are expected to be performed on each dosimeter and to relate the performance of each dosimeter to the type test data. Routine tests may also be used as acceptance tests.

One assumption of type testing is that the tested product sample represents the performance of the manufactured product. Thus any subsequent changes in the product will render the test data invalid unless it can be shown that the changes will not affect performance. This includes changes in components or hardware including their source of manufacture, and any changes in software algorithms used by the microprocessor. This can include add on devices such as telemetry units and testing should also be performed with these installed so that their impact on performance can be evaluated. Temperature and overload response are examples of parameters that can be affected by changes in components or algorithms. Changes should be reviewed by the testing laboratory or by another independent party to determine if type testing needs to be repeated. Routine tests, performance tests or calibrations may not be sensitive to changes caused by design changes or the introduction of new components.

An important limitation of type testing is the assumption that the test ranges in the testing standard represent the conditions in a specific users facility. Test ranges for some influence quantities may overqualify the ED for some facilities and not meet expected conditions in other facilities. The user must review the test data critically and request additional tests where it is felt necessary. One unfortunate trend is to test only at the extremes and assume that the performance varies linearly over the range of the influence quantities. Temperature is one example and is a variable that may not result in a linear variation of response and may not exhibit the same variation from unit to unit (Clement 1995, Swinth and Hickey 1988). Generally, design philosophy is to design just beyond the limits established in a standard and the testing laboratories test up to these limits, but not beyond. This is the reason that some test limits are presented to ensure test conditions remain within the limits (e.g. $+0 \%,-5 \%$ ).

During testing the performance of software/firmware is examined on the basis of overall performance of the ED. Thus the software/firmware is treated just as any hardware component in the ED. However, as noted elsewhere in this report the impact of errors in the software/firmware can be difficult to detect and may only occur when the ED undergoes manipulations that would not be normally expected. Thus testing should include some 
qualitative tests to determine if random operations can impact the performance of the ED. Examples of such testing may include repeatedly resetting the unit, repeated self tests, starting a process (calibration) and terminating it before the process is complete, etc. while observing the affect on dose rate and dose readings.

\subsubsection{Testing Methodology}

Testing is expected to be performed under a set of reference conditions using standard test methods and ensuring that results are statistically significant. Type testing standards include a set of reference conditions and a set of standard test conditions. Reference conditions are specific values of influence quantities while the standard test conditions are a range of values for these influence quantities. Tests are expected to be carried out under the standard test conditions or if this is not possible the values of the conditions (temperature, pressure, relative humidity) at the time of testing are to be stated and the response of the tested instrument corrected to reference conditions. For the type tests that are intended to determine the effects of variations in the influence quantities given in the reference and standard test conditions, all other influence conditions.should be maintained within the limits for the standard test conditions, unless otherwise specified in the test procedure. Thus one is examining the affect of one influence quantity at a time and assuming that the quantities are independent. This is not true for all variables; for example, angle of incidence and radiation energy. This is recognized in the standards by testing angle of incidence at multiple energies (usually $660 \mathrm{keV}$ and approximately $60 \mathrm{keV}$ ). The Germans (see Appendix A.6) test energy dependence at several angles fully recognizing the interdependence of the quantities.

Standards provide a test requirement which includes the range of variation of an influence quantity and the limits of the acceptable variation in performance over that range. In addition the standards include a testing methodology since the methods of test can also affect the response as a function of the influence quantity. For example, for temperature testing the full volume of the instrument must be allowed to stabilize at the test temperature. The testing times designated in ANSI N42.17A (ANSI 1989) are designed to accommodate this consideration. The study by Hodgson et al. (1988) shows the time needed for internal structures to come to temperature equilibrium on some instruments. Additionally, some tests must be carried out on a phantom to yield valid results.

The testing laboratory must be concerned with other corrections. For example, corrections may need to be made for calibrations and a scheme was suggested in Swinth et al. (1995). EDs are not linear with dose rate (due to dose rate correction algorithms) and if the energy response is tested at widely variable dose rates corrections may be necessary.

Since the response of instruments is expected to show some change due to the random variation in the rate of emitted radiation, statistical tests must be applied to evaluation of the data. On several tests the standards call for tests to be performed on higher scales where the statistical nature of the response will have a less significant affect on evaluation of the data. The standards will usually include guidance on the number of independent readings required to show a significant difference between a reference reading and one affected by an influence quantity. In general, changes of a few per cent are difficult to detect and such changes should not be considered significant unless they are considered in terms of a statistical analysis.

Detailed data analysis requires one to evaluate the variability of the data in addition to looking at the change in the mean response of the instrument. For ANSI N42.17 testing (Swinth 
and Kenoyer 1985a), the test data were used to calculate an acceptance rejection probability based on the cumulative normal distribution. If the acceptance-rejection probability ratio was not equal to or greater than 0.95 or not less than or equal to 0.05 , then the passage or failure of the individual instrument was identified as indeterminate. For comparisons against values that are known without error (conventionally true values, CTV), the measurement value $\pm 2 \sigma$ must fall within the limits defined by (1+acceptable range)X CTV and (1-acceptable range) X CTV. However, most standards compare criteria against a measurement at a reference value (i.e., ${ }^{137} \mathrm{Cs}$ for photon energy) thus the comparisons are measurement against measurement.

For most type testing standards it is required that each tested instrument meet the test criteria. The purpose of testing multiple units is to develop a level of confidence that the manufacturer is producing a consistent product. Failure of a single unit would normally require testing of a larger population similar to product acceptance testing. As noted earlier, examination of the temperature performance of a series of survey instruments demonstrated a lack of consistency of performance for some models (Swinth and Hickey 1988, Clement 1995). It has been proposed to examine the mean value of a series of measurements on EDs in the new draft of the ANSI N13.27 standard and test this value against the limits. Although the calculated confidence interval would provide an indication of the dispersion of the performance, such a move could mask the individual failures in a sample of EDs.

\subsubsection{Type Test Recommendations}

Table 1 compares several of the general performance criteria for EDs taken from four standards. Table 2 shows performance as a function of influence quantity for the same standards. Recommended performance criteria are highlighted in both tables. Although several of the standards may have the same specifications, only one set is highlighted with preference given to the IEC draft standard. Where a recommendation is not highlighted either a specific recommendation and rationale is included in this report or, if a recommendation is not included, it is felt the user can make his own judgment. The reader must reference the applicable standard for additional detail since it is not possible to provide all of the details included in the standard.

For reference the standards cited are Draft ANSI N13.27 (Performance Requirements for Pocket-Sized Alarm Dosimeters and Alarm Ratemeters, July, 1997), ANSI N42.20 (ANSI 1995), Draft IEC 1526 (Direct Reading Personal Dose Equivalent and/or Dose Equivalent Rate Dosemeters for the Measurement of Personal Dose Equivalent $H p(10)$ and $H p(0.07)$ for $X$, Gamma and Beta Radiations, November, 1995) and, NUREG/CR-6354 (Swinth et al., 1995). ANSI N42.17A (ANSI 1989) is another important type testing standard and is the basis for several specifications in both national and international type testing standards. The standard is not included in this comparison, but data may be obtained from the standard or from a similar comparison in NUREG/CR-6354 (Swinth et al. 1995). The ANSI N42.20 and Draft ANSI N13.27 standards are partially based on data taken from IEC standards, in particular, IEC 1344, "Radiation Protection Instrumentation-Monitoring Equipment-Personal Warning Devices for $\mathrm{X}$ and Gamma Radiations."

Some of the specific criteria suggested for characteristics in Tables 1 and 2 for which a highlighted preference is not given are noted below:

- For repeatability and reproducibility, the coefficient of variation at the $2 \sigma$ level should be $\leq 3 \%$ for a single unit and $\leq 7 \%$ for a sample of 10-15 units. As noted in 
Table 1: General characteristics and requirements for electronic dosimeters from four standards. Highlighted requirements are recommended requirements. For characteristics that do not have highlighted requirements see the report.

\begin{tabular}{|c|c|c|c|c|}
\hline CHARACTERISTIC & DRAFT ANSI N13.27 (7/97) & ANSI N42.20 (3/95) & DRAFT IEC $1526(4 / 96)$ & NUREG/CR-6354(7/95) \\
\hline $\begin{array}{l}\text { Size, } \mathrm{cm} \\
\text { (lengthXwidthXdepth) }\end{array}$ & $\begin{array}{l}15 \times 8 \times 3 \\
\text { excluding clip } \\
\end{array}$ & $\begin{array}{l}\text { Type 1: } 15 \times 8 \times 3 \\
\text { Type } 2 \& 3: 20 \times 10 \times 5\end{array}$ & $\begin{array}{l}15 \times 8 \times 3 \\
\text { excluding clip }\end{array}$ & $\begin{array}{l}15 \times 8 \times 3 \\
\text { excluding clip }\end{array}$ \\
\hline Mass & $\leq 200 \mathrm{~g}$ & $\begin{array}{l}\text { Type } 1: \leq 200 \mathrm{~g} \\
\text { Type } 2: \leq 300 \mathrm{~g} \\
\text { Type } 3: \leq 400 \mathrm{~g}\end{array}$ & $200 \mathrm{~g}$ & $200 \mathrm{~g}$ \\
\hline Case & $\begin{array}{l}\text { Smooth, rigid shock } \\
\text { resistant, dust proof Clip or } \\
\text { lanyard. Should enable } \\
\text { proper orientation }\end{array}$ & $\begin{array}{l}\text { Smooth, rigid shock resistant, } \\
\text { dust proof Clip or lanyard. } \\
\text { Should enable proper } \\
\text { orientation }\end{array}$ & $\begin{array}{l}\text { Smooth, rigid shock resistant, } \\
\text { dust and shower proof Clip or } \\
\text { lanyard. Should enable proper } \\
\text { orientation }\end{array}$ & $\begin{array}{l}\text { Smooth, rigid shock resistant, } \\
\text { dust and moisture proof Clip or } \\
\text { lanyard. Should enable proper } \\
\text { orientation }\end{array}$ \\
\hline Clip & $\begin{array}{l}500 \mathrm{gm} \text { clip load. Distance } \\
\text { from ED to surface clipped } \\
\leq 1 \mathrm{~cm}\end{array}$ & & & \\
\hline Controls & $\begin{array}{l}\text { Controls for turning } \\
\text { dosimeter off or for altering } \\
\text { integrated dose in memory } \\
\text { shall be protected from } \\
\text { unauthorized activation.... }\end{array}$ & $\begin{array}{l}\text { Switches protected from } \\
\text { accidental or unauthorized } \\
\text { operation. Switch operation } \\
\text { shall not interfere with dose } \\
\text { integration. Switches operable } \\
\text { through plastic bag/gloved hand }\end{array}$ & $\begin{array}{l}\text { Switches protected from } \\
\text { accidental or unauthorized } \\
\text { operation. Switch operation } \\
\text { shall not interfere with dose } \\
\text { integration. Switches operable } \\
\text { through plastic bag/gloved hand }\end{array}$ & $\begin{array}{l}\text { Switches protected from } \\
\text { accidental or unauthorized } \\
\text { operation. Switch operation } \\
\text { shall not interfere with dose } \\
\text { integration. Switches operable } \\
\text { through plastic bag/gloved hand }\end{array}$ \\
\hline Alarms, audible & $80 \mathrm{~dB}$ at $30 \mathrm{~cm}$ & $\begin{array}{l}\text { Audible frequency } 1-5 \mathrm{kHz} \text {. } \\
\text { Signal interval } \leq 2 \mathrm{~s} \text { for } \\
\text { intermittent alarm. Volume at } \\
\text { users ears }>85 \mathrm{~dB}(\mathrm{~A}) ; \mathrm{A}- \\
\text { weighted sound level } \\
\leq 100 \mathrm{~dB}(\mathrm{~A}) \text { at } 30 \mathrm{~cm}\end{array}$ & $\begin{array}{l}\text { Audible frequency } 1-5 \mathrm{kHz} \text {. } \\
\text { Signal interval } \leq 2 \mathrm{~s} \text { for } \\
\text { intermittent alarm. Volume at } \\
\text { users ears }>85 \mathrm{~dB}(\mathrm{~A}) \text {; A- } \\
\text { weighted sound level } \\
\leq 100 \mathrm{~dB}(\mathrm{~A}) \text { at } 30 \mathrm{~cm}\end{array}$ & $\begin{array}{l}\text { Audible frequency } 1-5 \mathrm{kHz} \text {. } \\
\text { Signal interval } \leq 2 \mathrm{~s} \text { for } \\
\text { intermittent alarm. Volume at } \\
\text { users ears }>85 \mathrm{~dB}(\mathrm{~A}) ; \text { A- } \\
\text { weighted sound level } \\
\leq 100 \mathrm{~dB}(\mathrm{~A}) \text { at } 30 \mathrm{~cm}\end{array}$ \\
\hline Alarms, disable & $\begin{array}{l}\text { Alarms shall be protected } \\
\text { form unauthorized } \\
\text { deactivation }\end{array}$ & $\begin{array}{l}\text { Alarm levels not settable by } \\
\text { external switches. Dose alarm } \\
\text { not subject to alteration by user. }\end{array}$ & $\begin{array}{l}\text { Alarm levels not settable by } \\
\text { external switches. Dose alarm } \\
\text { not subject to alteration by } \\
\text { unauthorized means. }\end{array}$ & $\begin{array}{l}\text { Alarm levels not settable by } \\
\text { external switches. Dose alarm } \\
\text { not subject to alteration by } \\
\text { unauthorized means. }\end{array}$ \\
\hline
\end{tabular}


Table 1 (cont.): General characteristics and requirements for electronic dosimeters from four standards. Highlighted requirements are recommended requirements. For characteristics that do not have highlighted requirements see the report.

\begin{tabular}{|c|c|c|c|c|}
\hline CHARACTERISTIC & DRAFT ANSI N13.27 (7/97) & ANSI N42.20 (3/95) & DRAFT IEC 1526 (4/96) & NUREG/CR-6354(7/95) \\
\hline Measurement Ranges & $\begin{array}{l}\text { Minimum range of } 1 \mathrm{mrem} \text { to } \\
10 \mathrm{rem}(1 \mathrm{mrem} / \mathrm{h} \text { to } 10 \mathrm{rem} / \mathrm{h})\end{array}$ & $\begin{array}{l}\text { Types } 1 \& 2: 0.1 \mathrm{mrem} \text { to } \\
100 \mathrm{rem}(1 \text { to } 100 \mathrm{mrem} / \mathrm{h}) \\
\text { Type } 3: 1 \mathrm{mrem} \text { to } 100 \mathrm{rem} \\
(1 \mathrm{mrem} / \mathrm{h} \text { to } 10 \mathrm{rem} / \mathrm{h})\end{array}$ & $\begin{array}{l}0.1 \mathrm{mrem} \text { to } 100 \mathrm{rem}(0.1 \text { to } \\
100 \mathrm{mrem} / \mathrm{h})\end{array}$ & $\begin{array}{l}0.1 \mathrm{mrem} \text { to } 100 \mathrm{rem}(0.1 \text { to } \\
1000 \mathrm{mrem} / \mathrm{h})\end{array}$ \\
\hline Background Response & $\begin{array}{l}\text { In background }(10 \mu \mathrm{rem} / \mathrm{h}) \\
<1 \text { mrem in } 8 \mathrm{hrs} \text { : for } \\
\text { sensitivity of } 0.1 \mathrm{mrem} \\
\leq 0.2 \mathrm{mrem} \text { in } 8 \mathrm{hrs} \text {. } \\
\end{array}$ & & $\begin{array}{l}\text { Use only components with } \\
\text { contribution of less than } \\
0.5 \mu \mathrm{Sv} / \mathrm{h} \text {. }\end{array}$ & $\begin{array}{l}\text { Use only components with } \\
\text { contribution of less than } \\
10 \mu \mathrm{rem} / \mathrm{h} \text {. }\end{array}$ \\
\hline Saturation & $\begin{array}{l}\text { Dosimeters for dose of } \\
\text { record: data in memory shall } \\
\text { be marked to show when } \\
\text { dose range is exceeded. } \\
\text { Manufacturer shall state } \\
\text { range within accuracy } \\
\text { requirements. }\end{array}$ & See overload test & See overload test & See overload test \\
\hline $\begin{array}{l}\text { Memory Protection } \\
\text { (Retention) }\end{array}$ & $\begin{array}{l}\text { Alarm levels, critical } \\
\text { information maintained in } \\
\text { nonvolatile state or otherwise } \\
\text { protected from loss by power } \\
\text { failure (dose also if used for } \\
\text { primary dosimetry) Clearing } \\
\text { or reset only by authorized } \\
\text { individual }\end{array}$ & $\begin{array}{l}\text { Integrated dose equivalent } \\
\text { shall not change more than the } \\
\text { greater of } 5 \% \text { or } 1 \text { mrem upon } \\
\text { replacement of the principal } \\
\text { voltage supply } 24 \mathrm{~h} \text { after loss or } \\
\text { interruption. }\end{array}$ & $\begin{array}{l}\text { Class 1: Retains dose under all } \\
\text { normal circumstances } \\
\text { Class 2: Dose information may } \\
\text { be lost if principal power supply } \\
\text { lost. }\end{array}$ & $\begin{array}{l}\text { Integrated dose equivalent shall } \\
\text { not change more than the } \\
\text { greater of } 2 \% \text { or a change in the } \\
\text { least significant digit upon } \\
\text { replacement of the principal } \\
\text { voltage supply } 24 \mathrm{~h} \text { after loss or } \\
\text { interruption. } \\
\text { Data shall be recoverable after } \\
\text { loss of display and } \\
\text { communicator (test provided) }\end{array}$ \\
\hline $\begin{array}{l}\text { Repeatability and } \\
\text { Reproducibility }\end{array}$ & $\begin{array}{l}\text { Coefficient of Variation; } \\
\text { single unit or population } \leq 3 \%\end{array}$ & $\begin{array}{l}\text { Variance in } 10 \text { sets of } \\
\text { exposures } \leq 5 \%\end{array}$ & & $\begin{array}{l}\text { Twice coefficient of variation of } \\
\text { population } \leq 10 \%\end{array}$ \\
\hline
\end{tabular}


Table 2: Requirements for tests performed with variation of influence quantities from four standards. The range of values for the influence quantities is shown in normal type; the limits of variation are in italics. Highlighted requirements are recommendations. For characteristics that are not highlighted see text.

\begin{tabular}{|c|c|c|c|c|}
\hline CHARACTERISTIC & DRAFT ANSI N13.27 (7/97) & ANSI N42.20(3/95) & DRAFT IEC $1526(4 / 96)$ & NUREG/CR-6354 (7/95) \\
\hline $\begin{array}{l}\text { Relative Intrinsic } \\
\text { Error }\end{array}$ & $\begin{array}{l}\text { Effective Range of Measurement } \\
\text { Dose equivalent } \pm 15 \% \\
\text { Dose equivalent rate } \pm 20 \%\end{array}$ & $\begin{array}{l}\text { Effective Range of } \\
\text { Measurement } \\
\text { Dose equivalent } \pm 15 \% \\
\text { Dose equivalent rate } \pm 20 \%\end{array}$ & $\begin{array}{l}\text { Effective Range of } \\
\text { Measurement } \\
\text { Dose equivalent } \pm 15 \% \\
\text { Dose equivalent rate } \pm 20 \%\end{array}$ & $\begin{array}{l}\text { Effective Range of } \\
\text { Measurement } \\
\text { Dose equivalent } \pm 10 \% \\
\text { Dose equivalent rate } \pm 15 \%\end{array}$ \\
\hline Response Time & Varies with dose rate, $2-30 \mathrm{~s}$ & $\begin{array}{l}5 s \\
+20 \% \\
\end{array}$ & $\begin{array}{l}5 \text { s for increase } \\
10 \text { s for decrease } \\
\pm 10 \%\end{array}$ & $\begin{array}{l}5 \mathrm{~s} \\
\pm 10 \% \\
\end{array}$ \\
\hline $\begin{array}{l}\text { Accuracy of Alarm } \\
\text { Levels }\end{array}$ & $\begin{array}{l}\text { All settings } \\
\text { Dose equivalent } \pm 15 \% \\
\text { Dose equivalent rate } \pm 20 \%\end{array}$ & $\begin{array}{l}\text { All settings } \\
\text { Dose equivalent } \pm 15 \% \\
\text { Dose equivalent rate } \pm 20 \% \\
\end{array}$ & $\begin{array}{l}\text { All settings } \\
\text { Dose equivalent } \pm 15 \% \\
\text { Dose equivalent rate } \pm 20 \%\end{array}$ & $\begin{array}{l}\text { All settings } \\
\text { Dose equivalent } \pm 15 \% \\
\text { Dose equivalent rate } \pm 20 \%\end{array}$ \\
\hline $\begin{array}{l}\text { Radiation Energy } \\
\text { Photon }\end{array}$ & $\begin{array}{l}80 \mathrm{keV}-1.25 \mathrm{MeV} \\
\pm 30 \%(a)\end{array}$ & $\begin{array}{l}50 \mathrm{keV}-1.5 \mathrm{MeV} \\
\pm 30 \% \%^{(a)}\end{array}$ & $\begin{array}{l}20 \mathrm{keV}-1.5 \mathrm{MeV} \\
\pm 30 \%(a)\end{array}$ & $\begin{array}{l}\text { Cat. } 1: 100 \mathrm{keV}-1.25 \mathrm{MeV} \\
\text { Cat } 2: 20 \mathrm{keV}-1.25 \mathrm{MeV} \\
\pm 30 \% \%^{(a)}\end{array}$ \\
\hline Beta & $\begin{array}{l}0.5-3.5 \mathrm{MeV} \\
\pm 50 \%\end{array}$ & $\begin{array}{l}\mathrm{E}_{\mathrm{max}}=3.5 \mathrm{MeV} \\
\pm 50 \%\end{array}$ & $\begin{array}{l}E_{\max }=0.78-3.5 \mathrm{MeV} \\
\pm 30 \%\end{array}$ & $\begin{array}{l}E_{\max } \geq 0.25 \mathrm{MeV} \\
\pm 30 \%\end{array}$ \\
\hline Neutron & $\begin{array}{l}\text { Provided by manufacturer as } \\
\text { correction factor }\end{array}$ & $\begin{array}{l}\text { Thermal to } 15 \mathrm{MeV} \\
\pm 50 \%\end{array}$ & Not specified & Not specified \\
\hline High Energy Photon & $\begin{array}{l}>1.25 \mathrm{MeV} \\
-50 \% \text { to }+100 \%\end{array}$ & & $\begin{array}{l}6 \mathrm{MeV} \\
-50 \% \text { to } \div 100 \%\end{array}$ & $\begin{array}{l}6 \mathrm{MeV} \\
-50 \% \text { to }+100 \%\end{array}$ \\
\hline $\begin{array}{l}\text { Angle of Incidence } \\
\text { Photon } \\
\text { Beta }\end{array}$ & $\begin{array}{l}-75^{\circ} \text { to }+75^{\circ} \\
\pm 20 \%(C s 137) ; \pm 50 \%(H 100) \\
\text { Not specified }\end{array}$ & $\begin{array}{l}-75^{\circ} \text { to }+75^{\circ} \\
\pm 30 \%(C s 137) ; \pm 50 \%(A m 241) \\
\text { Not specified }\end{array}$ & $\begin{array}{l}-60^{\circ} \text { to }+60^{\circ} \\
\pm 20 \%(C s l 37) ; \pm 50 \%(\text { Am 24I) } \\
-60^{\circ} \text { to }+60^{\circ} \\
\pm 30 \%(S r / Y)\end{array}$ & $\begin{array}{l}-60^{\circ} \text { to }+60^{\circ} \\
\pm 20 \%(C s l 37) ; \pm 50 \%(A m 241) \\
-60^{\circ} \text { to }+60^{\circ} \\
\pm 30 \%(S r / Y) \\
\end{array}$ \\
\hline $\begin{array}{l}\text { Dose Rate Equivalent } \\
\text { Dependence }\end{array}$ & $\begin{array}{l}\text { Up to } 1 \mathrm{~Sv} / \mathrm{h} \\
< \pm 20 \%\end{array}$ & $\begin{array}{l}\text { Up to } 1 \mathrm{~Sv} / \mathrm{h} \\
< \pm 20 \%\end{array}$ & $\begin{array}{l}\text { Up to } 1 \mathrm{~Sv} / \mathrm{h} \\
< \pm 20 \%\end{array}$ & $\begin{array}{l}\text { Up to } 1 \mathrm{~Sv} / \mathrm{h} \\
< \pm 10 \%\end{array}$ \\
\hline
\end{tabular}




\begin{tabular}{|c|c|c|c|c|}
\hline \multicolumn{5}{|c|}{$\begin{array}{l}\text { Table } 2 \text { (cont.): Requirements for tests performed with variation of influence quantities from four standards. The range of values for the influence quantities is } \\
\text { shown first; the limits of variation are in italics. Highlighted requirements are recommendations. For characteristics that are not highlighted see text. }\end{array}$} \\
\hline CHARACTERISTIC & DRAFT ANSI N13.27(7/97) & ANSI N42.20 (3/95) & DRAFT IEC 1526(4/96) & NUREG/CR-6354 (7/95) \\
\hline Overload & $\begin{array}{l}2 \text { times range maxima } \\
\text { Indication }>\text { full scale }\end{array}$ & $\begin{array}{l}2 \text { times range maxima } \\
\text { Indication }>\text { full scale }\end{array}$ & $\begin{array}{l}10 \text { times range maxima } \\
\text { Indication }>\text { full scale }\end{array}$ & $\begin{array}{l}10 \text { times range maxima } \\
\text { Indication }>\text { full scale }\end{array}$ \\
\hline $\begin{array}{l}\text { Interfering Ionizing } \\
\text { Radiation }\end{array}$ & $\begin{array}{l}\text { Operating conditions } \\
\text { Stated by mamufacturer }\end{array}$ & $\begin{array}{l}\text { At } 10 \mathrm{mSv} \\
<2.5 \% \text { of full scale }\end{array}$ & $\begin{array}{l}\text { Neutrons (Cf or } \mathrm{AmBe} \text { ) } \\
<5 \%\end{array}$ & $\begin{array}{l}\text { Neutrons (Cf or AmBe) } \\
<1 \%\end{array}$ \\
\hline $\begin{array}{l}\text { Mixed Field } \\
\text { Response } \\
\end{array}$ & Not specified & Not specified & Not specified & $\begin{array}{l}\text { Cs137 and/or T1204 } \\
\text { Additive within 1\% }\end{array}$ \\
\hline Retention of Reading & Not specified & $\begin{array}{l}24 \mathrm{~h} \text { after loss of principal } \\
\text { power supply } \\
\pm 5 \%\end{array}$ & $\begin{array}{l}8 \text { hours } \\
\pm 2 \% \\
24 \text { h after loss of principal } \\
\text { power supply } \\
\pm 5 \%\end{array}$ & $\begin{array}{l}8 \text { hours } \\
\pm 2 \% \\
24 \text { h after loss of principal } \\
\text { power supply } \\
\pm 5 \%\end{array}$ \\
\hline $\begin{array}{l}\text { Power Supply } \\
\text { Voltage } \\
\text { Primary Batteries } \\
\text { Secondary Batteries } \\
\end{array}$ & $\begin{array}{l}>100 \mathrm{~h} \text { continuous use } \\
\pm 10 \% \\
\text { Not Specified }\end{array}$ & $\begin{array}{l}>100 \mathrm{~h} \text { continuous use } \\
\pm 15 \% \\
>10 \mathrm{~h} \text { continuous use } \\
\pm 15 \%\end{array}$ & $\begin{array}{l}>100 \mathrm{~h} \text { continuous use } \\
\pm 15 \%{ }^{(b)} \\
>24 \mathrm{~h} \text { continuous use } \\
\pm 15 \%\end{array}$ & $\begin{array}{l}>2000 \mathrm{~h} \text { continuous use } \\
\pm 15 \% \%^{(b)} \\
>10 \mathrm{~h} \text { continuous use } \\
\pm 15 \%\end{array}$ \\
\hline Drop Tests & $\begin{array}{l}1.5 \text { meters, one face ( } 20 \text { units } \\
\text { or } 6 \text { from } 2.0 \text { meters) } \\
\pm 10 \%\end{array}$ & $\begin{array}{l}1.5 \text { meters, each face } \\
\pm 10 \%\end{array}$ & $\begin{array}{l}1.5 \text { meters, each face } \\
\pm 10 \%\end{array}$ & $\begin{array}{l}1.5 \text { meters, each face } \\
\pm 10 \%\end{array}$ \\
\hline Vibration Test & $\begin{array}{l}2.0 \mathrm{~g} ; 10-33 \mathrm{~Hz} ; 25 \mathrm{~min} \\
\pm 15 \%\end{array}$ & $\begin{array}{l}2.0 \mathrm{~g} ; 10-33 \mathrm{~Hz} ; 15 \mathrm{~min} \text { each axis } \\
\pm 10 \%\end{array}$ & $\begin{array}{l}2.0 \mathrm{~g} ; 10-33 \mathrm{~Hz} ; 15 \mathrm{~min} \text { each axis } \\
\pm 15 \%\end{array}$ & $\begin{array}{l}3.0 \mathrm{~g} ; 10-33 \mathrm{~Hz} ; 15 \mathrm{~min} \text { each axis } \\
\pm 15 \%\end{array}$ \\
\hline Microphony Test & Not specified & Not specified & $\begin{array}{l}\text { Drop } 10 \mathrm{~cm} ; 10 \text { times each face } \\
\text { Change in reading }<1 \mu \mathrm{Sw}\end{array}$ & Not specified \\
\hline $\begin{array}{l}\text { Ambient } \\
\text { Temperature Change }\end{array}$ & $\begin{array}{l}-10^{\circ} \mathrm{C} \text { to } 40^{\circ} \mathrm{C} \\
\pm 20 \% \\
-18^{\circ} \mathrm{C} \text { to } 50^{\circ} \mathrm{C} \\
\pm 50 \%\end{array}$ & & $\begin{array}{l}-10^{\circ} \mathrm{C} \text { to } 40^{\circ} \mathrm{C} \\
\pm 20 \% \\
-20^{\circ} \mathrm{C} \text { to } 50^{\circ} \mathrm{C} \\
\pm 50 \%\end{array}$ & $\begin{array}{l}-10^{\circ} \mathrm{C} \text { to } 40^{\circ} \mathrm{C} \\
\pm 10 \% \\
-25^{\circ} \mathrm{C} \text { to } 55^{\circ} \mathrm{C} \\
\pm 20 \% \\
0^{\circ} \mathrm{C} \text { to } 55^{\circ} \mathrm{C} \\
\pm 15 \%\end{array}$ \\
\hline
\end{tabular}


Table 2 (cont.) Requirements for tests performed with variation of influence quantities from four standards. The range of values for the influence quantities is shown first; the limits of variation are in italics. Highlighted requirements are recommendations. For characteristics that are not highlighted see text.

\begin{tabular}{|c|c|c|c|c|}
\hline CHARACTERISTIC & DRAFT ANSI N13.27(7/97) & ANSI N42.20(3/95) & DRAFT IEC $1526(4 / 96)$ & NUREG/CR-6354 (7/95) \\
\hline Temperature Shock & $\begin{array}{l}20^{\circ} \mathrm{C} \text { to/from } 50^{\circ} \mathrm{C} \&-10^{\circ} \mathrm{C} \\
\pm 15 \%\end{array}$ & $\begin{array}{l}20^{\circ} \mathrm{C} \text { to/from } 50^{\circ} \mathrm{C} \&-10^{\circ} \mathrm{C} \\
\pm 15 \%\end{array}$ & $\begin{array}{l}20^{\circ} \mathrm{C} \text { to/from } 50^{\circ} \mathrm{C} \&-10^{\circ} \mathrm{C} \\
\pm 15 \%\end{array}$ & $\begin{array}{l}20^{\circ} \mathrm{C} \text { to/from } 50^{\circ} \mathrm{C} \mathrm{\&}-10^{\circ} \mathrm{C} \\
\pm 15 \%\end{array}$ \\
\hline Relative Humidity & $\begin{array}{l}40 \% \text { to } 95 \% \mathrm{RH} \text { at } 35^{\circ} \mathrm{C} \\
\pm 15 \%\end{array}$ & $\begin{array}{l}40 \% \text { to } 95 \% \mathrm{RH} \text { at } 35^{\circ} \mathrm{C} \\
\pm 15 \%\end{array}$ & $\begin{array}{l}40 \% \text { to } 95 \% \text { RH at } 35^{\circ} \mathrm{C} \\
\pm 15 \%\end{array}$ & $\begin{array}{l}40 \% \text { to } 95 \% \mathrm{RH} \text { at } 35^{\circ} \mathrm{C} \\
\pm 15 \%\end{array}$ \\
\hline $\begin{array}{l}\text { Atmospheric } \\
\text { Pressure }\end{array}$ & No general specification & No general specification & No general specification & No general specification \\
\hline Electromagnetic Field & $\begin{array}{l}100 \mathrm{~V} / \mathrm{m} ; 100 \mathrm{kHz} \text { to } 500 \mathrm{MHz} \\
10 \mathrm{~V} / \mathrm{m} ; 500 \mathrm{MHz} \text { to } 1.0 \mathrm{GHz} \\
+10 \%(10 \mathrm{mrem} / \mathrm{h} \text { change })\end{array}$ & $\begin{array}{l}100 \mathrm{~V} / \mathrm{m} ; 100 \mathrm{kHz} \text { to } 500 \mathrm{MHz} \\
1 \mathrm{~V} / \mathrm{m} ; 500 \mathrm{MHz} \text { to } 1.0 \mathrm{GHz} \\
\pm 10 \%\end{array}$ & $\begin{array}{l}100 \mathrm{~V} / \mathrm{m} ; 100 \mathrm{kHz} \text { to } 500 \mathrm{MHz} \\
1 \mathrm{~V} / \mathrm{m} ; 500 \mathrm{MHz} \text { to } 1.0 \mathrm{GHz} \\
\pm 10 \%\end{array}$ & $\begin{array}{l}100 \mathrm{~V} / \mathrm{m} ; 100 \mathrm{kHz} \text { to } 500 \mathrm{MHz} \\
1 \mathrm{~V} / \mathrm{m} ; 500 \mathrm{MHz} \text { to } 1.0 \mathrm{GHz} \\
\pm 10 \%\end{array}$ \\
\hline Magnetic Fields & $\begin{array}{l}100 \mathrm{~A} / \mathrm{m} \text { at } 50 \text { or } 60 \mathrm{~Hz} \\
+10 \%(10 \mathrm{mrem} / \mathrm{h} \text { change })\end{array}$ & $\begin{array}{l}60 \mathrm{~A} / \mathrm{m} \text { at } 50 \text { or } 60 \mathrm{~Hz} \\
\pm 10 \% \\
800 \mathrm{~A} / \mathrm{m}, \text { switched } \\
\pm 20 \%\end{array}$ & $\begin{array}{l}60 \mathrm{~A} / \mathrm{m} \text { at } 50 \text { or } 60 \mathrm{~Hz} \\
\pm 10 \%\end{array}$ & $\begin{array}{l}60 \mathrm{~A} / \mathrm{m} \text { at } 50 \text { or } 60 \mathrm{~Hz} \\
\pm 10 \%\end{array}$ \\
\hline Electric Fields & $\begin{array}{l}\leq 5000 \mathrm{~V} / \mathrm{m} \text { or } \leq 100 \mathrm{~V} / \mathrm{m}(60 \text { and } \\
400 \mathrm{~Hz}) \\
\pm 15 \% \text { or } 15 \mathrm{mrem} / \mathrm{h}\end{array}$ & $\begin{array}{l}5000 \mathrm{~V} / \mathrm{m} \\
\pm 20 \% \\
\end{array}$ & Not specified & Not specified \\
\hline Microwave Fields & $\begin{array}{l}\leq 100 \mathrm{~W} / \mathrm{m}^{2} \text { at } 0.915 \& 2.45 \mathrm{GHz} \\
\pm 15 \%\end{array}$ & Not specified & Not specified & Not specified \\
\hline $\begin{array}{l}\text { Electrostatic } \\
\text { Discharge }\end{array}$ & $\begin{array}{l}6 \mathrm{kV} ; 2 \mathrm{~mJ} ; 10 \mathrm{~s} \text { intervals } \\
+10 \% \text { or } 10 \mathrm{mrem} / \mathrm{h}\end{array}$ & $\begin{array}{l}6 \mathrm{kV} ; 2 \mathrm{~mJ} ; 10 \mathrm{~s} \text { intervals } \\
\pm 10 \%\end{array}$ & $\begin{array}{l}8 \mathrm{kV} ; 2 \mathrm{~mJ} ; 10 \mathrm{~s} \text { intervals }(\mathrm{c}) \\
\pm 10 \%\end{array}$ & $\begin{array}{l}6 \mathrm{kV} ; 2 \mathrm{~mJ} ; 10 \mathrm{~s} \text { intervals } \\
\pm 10 \%\end{array}$ \\
\hline $\begin{array}{l}\text { Splash/Rain } \\
\text { Resistance }\end{array}$ & $\begin{array}{l}4 \mathrm{~L} / \mathrm{min} \text { spray; } 1 \mathrm{~h} \\
\pm 15 \%\end{array}$ & $\begin{array}{l}4 \mathrm{~L} / \mathrm{min} \text { spray; } 2 \mathrm{~min} . \\
\pm 15 \%\end{array}$ & $\begin{array}{l}\text { "Sealing" Manufacturer to state } \\
\text { and test }\end{array}$ & $\begin{array}{l}0.6 \mathrm{~cm} \text { rain } / \mathrm{h} ; 2 \mathrm{hrs} . \\
<1 \% \text { change }\end{array}$ \\
\hline Light Exposure & Not specified & Not specified & Not specified & $\begin{array}{l}10,000 \mathrm{ft} \text {-candles; halogen lamp } \\
\text { No chonge }\end{array}$ \\
\hline Light Flash & Not specified & Not specified & Not specified & $\begin{array}{l}100 \mathrm{~W}-\mathrm{s} ; 10 \text { times } \\
\text { No change }\end{array}$ \\
\hline
\end{tabular}

NOTES: (a) All percentages are the acceptable limits of the variation of indication from the values under standard test conditions unless otherwise stated.;

(b) Limit of variation from initial indication.

(c) Expected to be changed from $6 \mathrm{kV}$ to $8 \mathrm{kV}$ in final version of standard. 
NUREG/CR-6354 testing should look at a sample of units (15) for the bias and coefficient of variation compared to the conventionally true value used in the testing laboratory. This permits the testing lab to evaluate the quality of the calibration by the manufacturer and to use the measured deviations to correct the readings during testing and thus eliminate any bias introduced by differences in the manufacturers and test laboratories differences in source calibrations.

- For photon energy a second category is appropriate due to the absence of low energy photons in some environments (see section 2.3.1). Although a higher minimum energy is listed for category 1 in table 2 , it is recommended that the energy range be extended to cover from $60 \mathrm{keV}$ to $1.25 \mathrm{MeV}$. Primarily because this larger energy range can be readily realized with current technology.

- For drop testing, the drop height should be increased to 1.75 meters (see section 2.3.3) to better represent the potential drop height in the work place. Many current models can meet this specification and one vendor voluntarily increased the test height to $1.9 \mathrm{~m}$ (see Appendix A.5) .

- The electromagnetic field testing should be changed to represent the increases in the electromagnetic field environment encountered in the workplace (see section 2.3.4). Testing should be done with a modulated carrier at $100 \mathrm{~V} / \mathrm{m}$ from $300 \mathrm{kHz}$ to $30 \mathrm{MHz}, 70 \mathrm{~V} / \mathrm{m}$ from 30 to $300 \mathrm{MHz}$ and again at $100 \mathrm{~V} / \mathrm{m}$ above $300 \mathrm{MHz}$.

- Although no general specification is given for ambient pressure, one should be considered with the advent of the direct ion storage based system (Wernli 1996). The test requirement from ANSI N42.17A (ANSI 1989) should be used ( $\leq 15 \%$ change from 70 to $106 \mathrm{kPa}$

referenced to $101 \mathrm{kPa}$ )

Tests should also be performed on the reader so that expected ranges of influence quantities will not affect data transfer accuracy. Swinth et al. (1995) recommend a set of tests for the reader with variation of influence quantities. Note that these tests are intended to be a test of the data transfer capability not the overall performance of the reader.

\subsubsection{Routine Tests (Manufacturer Testing)}

Selected tests from the standards can be used for routine tests by the manufacturer and can also be used in acceptance testing (see Tables 1 and 2). The tests can also be used by the manufacturer to test a sample of the product. Although a routine test requires the testing of all devices, testing of samples of the production units may be adequate for the manufacturer's quality control. The frequency of such testing should depend upon the manufacturing process, the consistency demonstrated in type tests, and any changes in components or suppliers during production. It is recommended that intrinsic error (calibration) and drift or stability of response is tested on a routine basis. A simplified form of energy response testing (single low energy point) should also be performed on a routine basis and may be part of the calibration. The microphonic response and radio-frequency susceptibility should be tested on a sampling basis or routinely depending on the experience of the users and manufacturers in the consistency of product performance. Other tests should be performed on a sampling basis to ensure consistency of suppliers and production. This should include simplified forms of energy response, angular response, drop tests, temperature response and humidity response. These are important since something as simple as a change of materials in the case or compensation filters by a supplier can affect the energy response. 


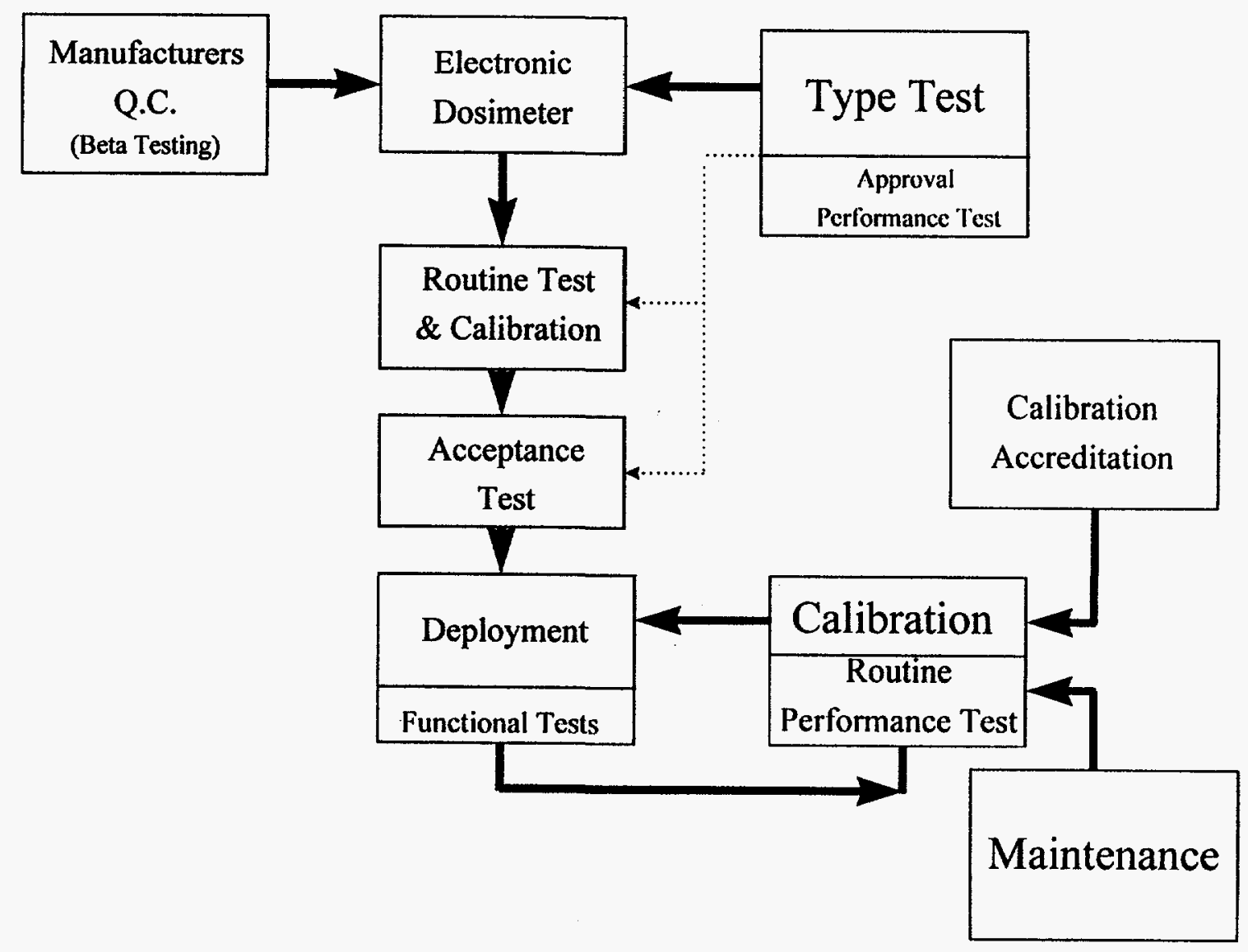

Figure 1: Relationship of the performance control activities for electronic dosimeters.

An important set of routine tests are the electrical tests performed on the manufactured product and the components or assemblies from suppliers. The ED must be performing correctly in terms of its electrical performance before routine tests of its radiological performance can be made. These and all other tests should be documented and available to the customer.

The routine tests can be related to the type tests as illustrated by the dotted lines in Figure 1. The first step is to establish a fixture during type testing which will hold the electronic dosimeter in a reproducible geometry. The fixture should also have fixed positions for test sources and be provided with a low-energy $\left({ }^{241} \mathrm{Am}[60 \mathrm{keV}]\right.$ or $\left.{ }^{57} \mathrm{Co}[122 \mathrm{keV}]\right)$ and a high-energy $\left({ }^{137} \mathrm{Cs}[660\right.$ $\mathrm{keV}$ ) source. The ratio of the source responses at normal incidence will provide assurance that the energy response is correct, while tests at $\pm 60^{\circ}$ from normal incidence (or greater) will test the angular response. This type of simplified routine testing is compatible with the recommendations in The Examination and Testing of Portable Radiation Instruments for External Radiations (HSE 1990). The fixture plus sources can be placed in an environmental chamber for temperature testing. 
The manufacturer has an important role in establishing, and maintaining ED reliability and in reliability growth. The reliability of the ED is a function of design, testing, component reliability, and manufacturing processes. The user has little control over these elements and following initial testing and evaluation relies upon the manufacturer to establish processes and quality control that will ensure continued (or improving) product reliability. Manufacturers have several means to improve product performance/reliability. Proper design can assist with general reliability and "product reliability/growth testing" is an accepted way to improve the reliability of the design. Testing of prototypes in the field (beta testing) is a good way of finding design limitations and is widely employed in the software development cycle. Methods of testing products and eliminating early failures are well known and, in some cases, required by contract. A "burn-in" period of operation at an elevated temperature will eliminate some early failures. The Navy has an established reliability screening program (DON 1979) consisting of temperature cycling and random vibration. For high-value products where field repairs will be costly or where high reliability is demanded by the application, such $100 \%$ screening (environmental stress screening, ESS) is important (Kececioglu 1995).

Recommendations for manufacturer reliability screening are beyond the scope of this report and are the responsibility of the manufacturer. However, the user may want to review reliability data and manufacturer reliability growth programs. Success of the ED as a primary dosimeter may depend on reduction of failures. At the present time, manufacturers do not have formal reliability growth programs.

\subsubsection{Foreign Programs}

Apart from Germany, in countries examined, formal type tests against specific criteria are not an explicit part of the approval process for dosimetry systems (see appendix A). However, in the case of the United Kingdom examination of performance data for a proposed system to be used by a dosimetry service would be an integral part of the approval process. Manufacturers visited do have type test data and in some cases have data from several sources plus supplementary data. Unfortunately, type testing data was not easily obtained from some of the manufacturers. In most cases the type test data examines the dosimeter performance in comparison to drafts of the International Electrotechnical Standards (IEC) relevant to the ED.

For the manufacturers visited (see Appendix A), the routine testing consists of specific electrical tests on the product plus an on-line calibration. Testing may include microphonic testing against criteria in the IEC $1526 \mathrm{draft}$, radio-frequency interference testing with a hand held transceiver and long term operational stability testing (see appendix A). All of the manufacturers had ISO 9000 certified quality assurance programs thus ensuring adequately documented processes.

\subsection{User Field Testing}

When a user proposes to use an ED for the dose of record, field testing and an examination of dosimetry records is suggested. Two situations may arise. First, the user has an existing electronic dosimetry program they would like to use for primary dosimetry or, second, the user proposes to implement a new ED system. In either case the user should examine the field performance of the proposed system by discussions with other users and most importantly by examination in his own facility. The facility specific examination is important since the radiofrequency fields (intensity and/or frequency) can vary dramatically. Examination should also include a review of passive dosimetry results to ensure that beta and low energy photon fields will 
not be a concern or if such concerns are limited to specific areas of the facility thus allowing other methods of control for those areas. The review should also include identification of existing or potential high dose rate situations where the ED would not be appropriate. Some models of EDs have adequate beta and low energy response. For a new system, field testing will also answer such questions as worker acceptance, audibility of alarms, compatibility with work processes (potential interference from microwaves, lasers, arc welding, chemicals, magnets, etc.), and help identify training and work integration issues.

Comparison of electronic dosimetry and passive dosimetry results is an important aspect of user field testing. Before implementing a dosimetry program based on the $\mathrm{ED}$, comparisons with the existing system are important to ensuring compatibility of records and comparable performance. During comparisons one must be aware of the differences in the minimum recording levels of the different systems. The lower recording level of the typical ED (0.1mrem vs approximately $10 \mathrm{mrem}$ for a TLD) will permit the ED to record a lower integrated exposure. However, in the case of low dose rates which are constant, the resetting of the ED on every entry may result in a lower accumulation on the ED. These factors must be considered and it may be most appropriate to limit comparisons to outages in a nuclear plant or to dose rate areas of about $1 \mathrm{mrem} / \mathrm{h}$ or greater where doses per entry would be expected to be 1-2 mrem or greater. Comparisons should include both individual comparisons of passive and active dosimetry and comparison of cumulative performance. Examining only cumulative performance may mask important individual discrepancies. Discrepancies above some limit (10mrem or $20 \%$ ) for individual doses of greater than say $30 \mathrm{mrem}$ need to be resolved.

\subsection{Acceptance Tests}

Each ED should be acceptance tested. This requires testing against specific purchasing specifications to ensure that such specifications are met. Acceptance tests can be related directly to type tests if an appropriate geometry is established as discussed in section 3.2.4. Generally, acceptance testing will consist of checking the calibration and sampling performance against selected criteria as deemed necessary. An acceptance test, which should precede the initial instrument calibration, should consist of (1) a physical inspection, (2) general operations tests, and (3) source tests. The physical inspections and general operations tests should be performed on each ED. The source tests should be performed on a random selection of approximately $10 \%$ of the EDs. If one unit in a sample from a large quantity fails the test, an additional $10 \%$ should be tested. An additional failure would require testing (or return to the vendor) of the entire batch.

Physical Inspection. This consists of general inspection for placement of labels, physical damage, shaking to detect loose internal parts, testing of moving parts (clips, switches, etc.), and making sure batteries are fresh and properly installed.

General Operation. The ED should be cycled through all of its modes of operation, including self-test sequences, data transfer to a reader, and operability of internal test circuits (background counting).

Source Tests. The ED should be tested for response to a source, reproducibility of readings (exposed to the same dose/dose rate several times), stability, temperature response, humidity response, angular response, and photon energy response. As noted under manufacturer quality control, if suitable tests are established during type-testing, the user can rapidly ensure 
performance compliant with type-testing performance with single point tests.

Instrument Calibration. The initial ED calibration is part of the acceptance test and should include a comparison of instrument linearity and overload response against specifications. Each ED should be calibrated.

\subsection{Calibrations and Periodic Performance Tests}

Examining the calibration or adjusting the calibration of the ED is important and should be performed periodically. Although not specifically written for electronic dosimeters, the recommendations of ANSI N323 (ANSI 1997) for calibration may be followed. A standard that is specific for EDs is needed. The new ANSI N323 standard includes guidance for dose rate and integrating instruments that are applicable; relevant guidance is incorporated into the steps listed below. However, when the ED is used for dosimetry, the appropriate dose equivalent conversion factors must be applied and the calibration must be performed on a phantom. The factor to convert air kerma to dose equivalent is 1.21 for ${ }^{137} \mathrm{Cs}$ (Martin 1996). Calibration should be performed a minimum of once a year.

\subsubsection{Precalibration}

Precalibration should include a visual examination of the ED condition and documentation of the instrument response upon return from the field by obtaining "as found" readings for the most common dose ranges. "As found" readings should be taken prior to any adjustments on the instrument unless the ED is returned in an inoperable condition. If the precalibration shows that the instrument is out of calibration in excess of some predetermined value, the radiation protection organization should be notified and the doses registered with the device investigated and corrected as necessary. The DOE implementation guide (DOE 1994) sets the limits at $\pm 20 \%$.

\subsubsection{Calibration}

The first step in calibration (when possible) should be examination and setting of all electrical parameters (voltages, switch settings, software switches, etc.) within manufacturer's specifications. The initial examination may also include a test of r.f. susceptibility, microphonic response, etc. depending on experience with the particular model. If problems are noted the instrument should be sent for repair prior to calibration. Then the actual calibration should proceed.

Calibration Based on Dose. Instruments which integrate dose shall be checked at a minimum of two dose rates at approximately $20 \%$ and $80 \%$ of the stated dose rate range or as recommended by the manufacturer. The integrations shall continue to a value sufficient to assure a statistically valid reading which shall be within $10 \%$ (15\% in ANSI N323) of the CTV. For digital instrumentation, integration should be checked to the maximum reading, obtainable on the display. If it is not practical to accomplish the full-scale radiological integration, the electronics and display may be checked electronically at the maximum integration point and with the radiological integration being performed at a lower point. Thus, one would select a high- and a low-dose rate and integrate the dose until a "reasonable" reading is obtained. Although ANSI $\mathrm{N} 323$ (1997) calls for integration to the maximum value, this may not be practical and electronic checking of the readout may be deemed sufficient. Integration should test to values that are expected in the workplace.

Following the initial test, the calibration factor (or control) should be adjusted as necessary and the calibration process repeated until the 
deviation from the CTV is within acceptable limits. Since the ED may not be linear at higher dose rates it is important to follow the manufacturer's recommendations for dose rates and adjustment of the calibration. An overresponse of $10 \%$ may be expected at higher dose rates due to compensation for dead time effects.

\section{Calibration Based on Dose Rate. If the} instrument is calibrated based on dose rate and is a linear readout instruments with a single calibration control for all scales, it shall be adjusted either at the point recommended by the manufacturer or at a point within the normal range of use. Instruments with calibration controls for each scale shall be adjusted on each scale. The same principles should be applied to microprocessor-controlled instruments. For instruments that also use a dead-time adjustment or setting, this adjustment should be made at the same time the calibration adjustment is performed. Dead-time adjustments should comply with the recommendations of the manufacturer. After adjustment, the response of the instrument shall be checked near the end points of each scale (approximately $20 \%$ and $80 \%$ of full scale). Instrument readings shall be within $\pm 10 \%$ of conventionally true values (CTV) at these two points. Following this sequence the dose function should be checked as above.

Calibration Geometries. The primary calibrations should be performed on a phantom in a low-scatter geometry. Calibrations will require the use of a collimated source $\left({ }^{137} \mathrm{Cs}[660 \mathrm{keV}]\right.$ is recommended) in an open air geometry. Primary calibrations of EDs should follow the recommendations of ISO-4037 (1979) for source and calibration geometry. Calibration of reference fields is generally performed with an ion chamber having a flat energy response; the ion chamber will be insensitive to variations in the low energy component but the ED mar be affected by the same changes. Since most EDs have poor low- energy response, their calibration will be sensitive to changes in scattered radiation and attention must be paid to ensuring a low and unchanging scatter geometry. Alternatively, EDs properly calibrated in an accredited calibration laboratory can be used to transfer the calibration to a "box calibrator" or other geometry with or without a phantom. This practice is recognized and described in the Health Physics Society accreditation criteria (Section C.10.6) ${ }^{8}$ for tertiary laboratories. This is the practice used by the manufacturers in the original calibration of the EDs. A series of so called "golden EDs" are calibrated at a qualified laboratory and used to transfer the calibration to a production calibrator. In one example the manufacturer routinely checks the calibration process by testing a sample of production units in a low scatter geometry (Appendix A).

Some EDs are adjusted during calibration by the manufacturer using a complex iterative process (Siemens 1994). It is not practical for the user to duplicate this process, but the calibration should be designed to ensure continued accuracy of ED performance and elimination of EDs that no longer maintain the $\pm 10 \%$ accuracy noted in ANSI N323 (ANSI 1997). Siemens also produces a source check device that will permit adequate performance testing of their EDs.

\subsubsection{Performance Tests}

Functional tests are not intended to test the accuracy of ED performance. Periodic performance tests should be performed to ensure that the ED is operating within a prescribed range of performance. For EDs, this may consist of a monthly test of response to a standard source or sources at known dose and dose rates representative of conditions in the work environment. This may be done in a standard

\footnotetext{
8 "Criteria for Accreditation of Calibration Laboratories by the Health Physics," available from the Health Physics Society, McLean, Virginia.
} 
fixture designed to deliver a known reading (see section 3.2.4) and the ED should be tested against specific limits (e.g. $\pm 10 \%$ ). This differs from a calibration in the depth of the examination. Failure to meet these specifications will require recalibration of the ED and an investigation of doses recorded by the ED since the last successful performance test.

Some vendors sell devices suitable for source checking their EDs (Siemens 1994). In many cases, these are suitable to ensure that the ED is performing within the accuracy specified at calibration.

\subsection{Functional Tests}

Functional checks of the ED should be performed periodically. Functional checks are often qualitative and will include source checks, electronic tests, etc. Many EDs have internal check functions and integrate normal background radiation to determine that the detector and electronics remain functional. These are deemed adequate in lieu of source checks, which are recommended "daily or before each use" in ANSI N323 (ANSI 1997). If the units do not perform the internal background tests on each detector, frequent source checks should be performed. The recommended frequency is daily or before each use for primary dosimeters to ensure that loss of data is minimized.

Even if the ED performs frequent self checking by background counting or light pulses on the detector (methods that test the entire system), a source check should be performed before entering a high radiation area (a daily check is adequate). Alternatively, supplemental dosimetry may be issued.

\subsection{Maintenance}

The EDs used as primary dosimeters should not be repaired or altered by the user. To maintain the necessary quality, damaged or malfunctioning EDs should be returned to the manufacturer for repair. Alternatively, factory qualified technicians may be permitted to exchange batteries and perform selected repairs such as replacement of assemblies (displays) and damaged hardware such as cases. Repaired devices shall be tested and calibrated to ensure performance comparable to new EDs. One of the critical tests is to test the r.f. susceptibility of repaired units and this test should be performed and documented following all repairs. Opening the case can damage the integrity of the shielding and there have been reports of increased r.f. susceptibility following modification or repair of dosimeters.

\subsection{Design Changes and Anomalous Performance}

Although mentioned previously the issue of design changes is important enough to be mentioned a second time. All designs of both hardware and software should be given a unique identification number including software used in the readers and data storage/transfer systems. Changes in the hardware including changes in supplied components should be documented and either reviewed by a technical expert to certify it will not affect performance or the type tests should be repeated. The same actions should be instituted for software changes in the ED. Changes in the readers and data storage/transfer systems should be tested by testing the integrity and reliability of the data transfer and storage. All tests and changes should be documented. Users and third party assessors should be notified of all changes in hardware, and software and any impact on dosimeter performance. 
On occasion faults will be discovered in the field that may affect the reliability of the data or alarms of the ED. All such problems should be reported to the manufacturer and to the regulatory agency who should issue an information notice or recall notice depending upon the seriousness of the fault. A recall may be needed if the fault will result in complete loss of data or failure to alarm in dangerous dose rates.

\subsection{Third Party Testing and Auditing}

Testing and auditing of dosimetry systems by a third party (independent of the user and manufacturer) is valuable for a system that constitutes the legal record of a worker's exposure. There are various approaches to the testing and auditing of dosimetry systems used throughout the industry (world). The purpose of this section is to examine some general features of the systems in use and how they might be used with the ED.

\subsubsection{U.S. Accreditation Programs}

Early recognition of problems in the personnel dosimetry programs led to the development of the NVLAP program for personnel dosimetry and the Department of Energy program for accreditation of dosimetry programs (Swinth et al. 1995). The NVLAP program accredits the dosimetry service; the DOELAP program accredits the user including the records system. The NVLAP program has been material in the improvement of the performance of the dosimetry systems in the U.S. Performance in all categories has shown continuous improvement over the past years (Martin 1996b). The five year average of the tolerance limit (bias + standard deviation) for deep dose categories, with the exception of low energy photon contributions, is currently less than 0.15 . The recent introduction of neural network algorithms in place of decision tree algorithms has brought the tolerance limit below $7 \%$ (Tawil
1996) on DOELAP test categories. Thus the bias and precision terms tested by the programs are well within the uncertainties one would require of a dosimetry system (ICRP 1982). The programs now need to only monitor the continuing quality of the dosimetry programs and many feel that they are an expensive means of performing that task.

Groups within the U.S. also operate calibration accreditation programs which may be appropriate to the ED since we have seen in previous sections that calibration is important to the maintenance of the performance of the ED. NVLAP operates a program for calibration programs to accredit secondary radiation calibration laboratories with direct traceability to NIST. Originally intended for Federal calibration laboratories it is open to all applicants (Eisenhower 1991). The Health Physics Society ${ }^{9}$ operates a calibration accreditation program for secondary and tertiary level laboratories with direct traceability to NIST(Swinth, et al. 1988). The NVLAP program does not include provisions for use of dosimeters as transfer standards or the use of high scatter geometries such as wells or box calibrators. Presently, operational costs of the HPS program are much lower than for the NVLAP program due to the use of volunteer assessors (Swinth, et al. 1988).

\subsubsection{Foreign Approaches to Third Party Oversight}

Type testing is not required by Great Britain or France at this time. However, France is preparing to accredit the type testing laboratories. See appendix A.3 for more information. France does not have third party oversight on electronic dosimetry systems. Great Britain has third party oversight through the Health and Safety Executive (HSE) which approves dosimetry services. The approval process involves a proficiency test that

\footnotetext{
${ }^{9}$ The Accreditation Criteria and program information are available from the Health Physics Society, McLean, VA 22101 (Attn. Nancy Johnson).
} 


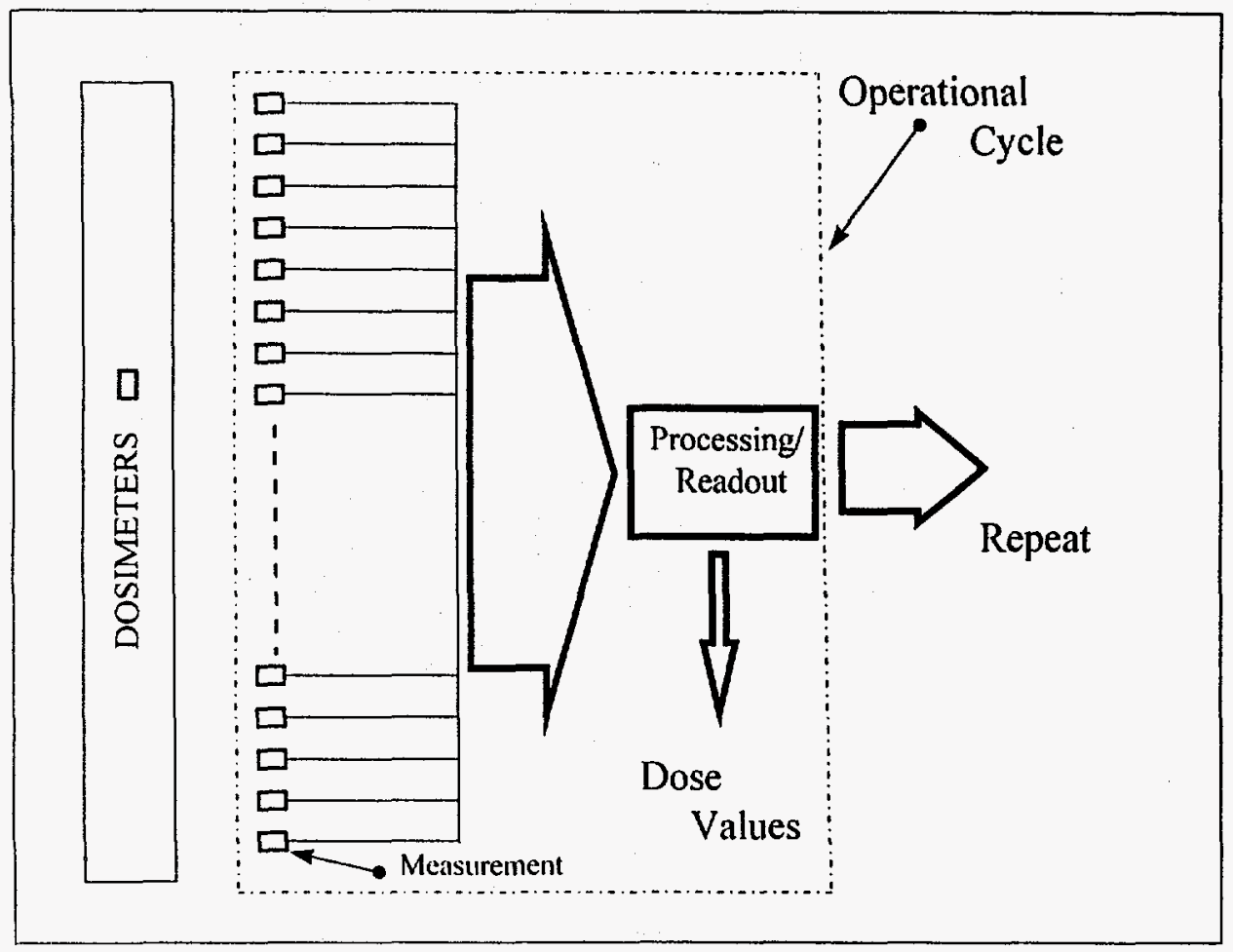

Figure 2: Illustration of the flow of processed dosimeters showing that their readout depends on a common process. This provides a defined point for quality control activities and performance testing.

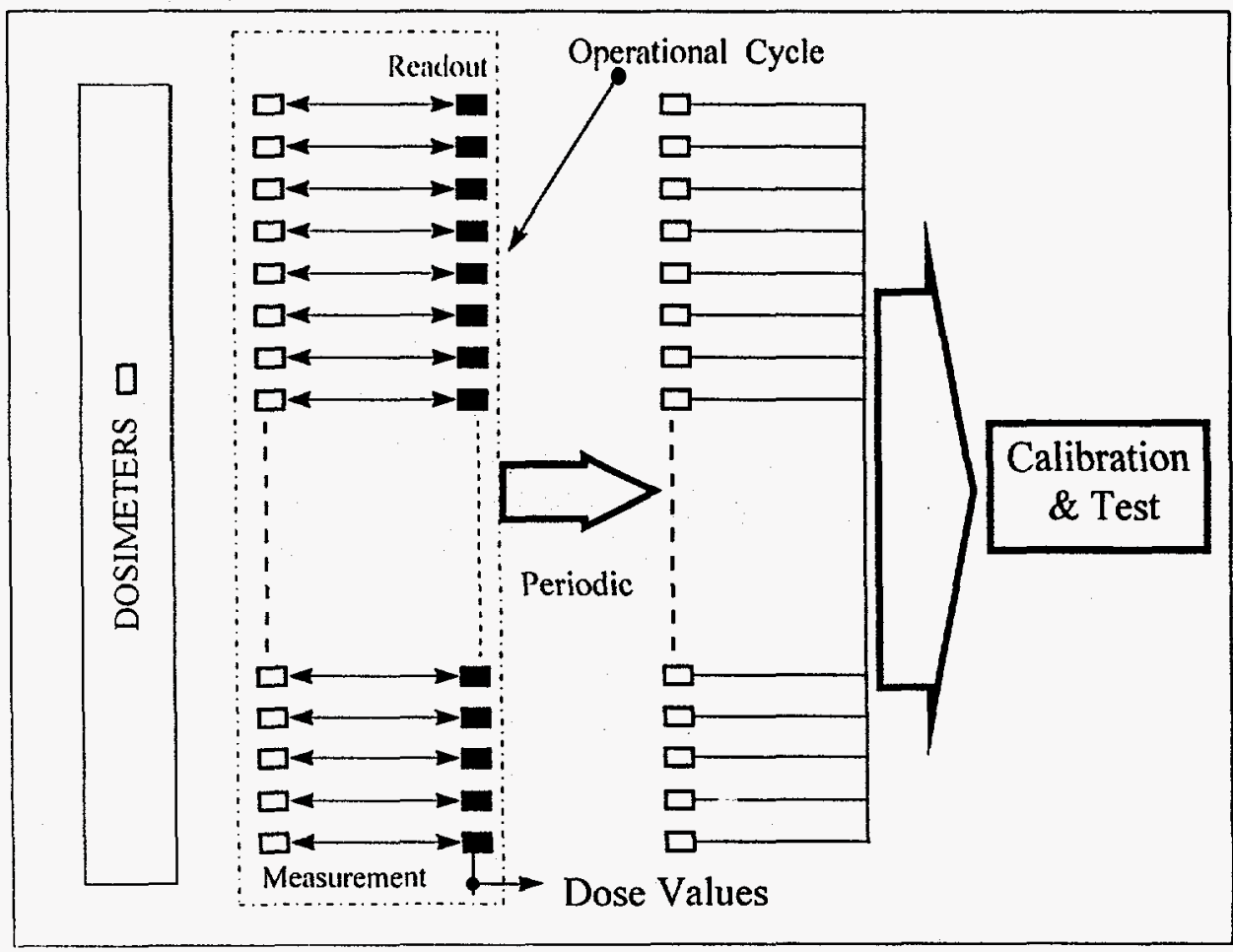

Figure 3: Illustration of the flow of electronic dosimeters showing they are not dependent on a common processing stage. Calibration is a common quality control point for the electronic dosimeter. 
the laboratory seeking approval can obtain through an accredited laboratory. Testing is repeated every 18 months. Approval also involves a site visit during which the process is examined and the dosimeter is examined to ensure that it is suitable for the environments in which it will be used. Approval is for a specific device with specific software; changes would require a new approval.

In the future the system in Germany will provide for primary dosimetry using EDs. Approvals will be based on the total uncertainty of the dosimetry system as determined by a pattern test (See appendix A.6) conducted by the Physikalish Technisches Bundesanstalt (the German counterpart of NIST). Approval is for a specific system and changes would require a new approval. Periodic tests (approximately every 24 months) are planned to ensure the continued reliability of the system.

\subsubsection{Discussion of Approaches}

Figure 2 illustrates the NVLAP performance test process. Since all passive dosimeters go through a central processing step to retrieve the data, the examination of this process by testing it with dosimeters bearing a known exposure tests the quality of the entire program. The dosimeters are a physical entity whose response depends upon the physical and material properties of the dosimeter. Any calibration for the individual dosimeters (chips) is handled during the processing. In contrast, Figure 3 shows the same process applied to the electronic dosimeter. Since the ED can be read out directly, both the exposure and the reading must be handled by the testing laboratory. The test is only examining the performance of the manufacturer's design and the quality of the calibration of the unit. Unless the design changes the only possible variable (aside from degradation or damage) is the calibration. If the hope is to find problems that develop during use one only need examine the statistics. If 10 out of a 1000 EDs change in performance, the probability of finding one of these units in a sample of 10 from the population is only $9 \%$. The probability of finding 2 is less than $1 / 2 \%$ ! In all probability a single defective unit would probably be dismissed. The same arguments can be applied to the inconsistency of calibrations.

As noted by Bartlett (1993), "Ascertainment of the repeatability and stability of measurement of individual dosemeters [EDs] issued for periods up to a year will replace assessment of batch characteristics of dosemeters issued for shorter periods." Hirning (1995) also notes the inappropriateness of the NVLAP and DOELAP programs for accreditation of active dosimeters and cites the lack of an appropriate program as an impediment to acceptance of active dosimetry. The critical point for the ED is the calibration and associated routine performance test program. As shown in Figure 3, the calibration is the common point for EDs and accreditation efforts, if undertaken, should be focused at this point.

The foreign processes are based on an initial comprehensive evaluation with follow-on tests to examine quality control and seems to be a valuable and cost effective approach. One approach would be to perform comprehensive tests on models of EDs that are candidates for primary dosimetry including both type tests and approval performance tests based on NVLAP (or DOELAP) test categories. These tests need to be performed only once for each model (including a specific version of software) and may be best sponsored by the manufacturer. The approval performance testing should be done by a NVLAP proficiency testing laboratory at the time of the type testing. The type testing should either be done by an independent third party or, if performed by the manufacturer, should be reviewed by an expert. This review could be part of the user's approval process. This will define a performance envelope for the dosimeter. 
Next the user must select the appropriate dosimeter for his work environment and design a program to ensure the reliable use of the dosimeter. The program design and appropriateness of the selected ED should be reviewed through a review of documentation and an on-site visit. An important point with regard to on-site visits is the division between the accreditation of calibration or processing and the accreditation of the operational health physics program. Should the accrediting organizations review the operational deployment of the dosimeters? This step could either be handled through a regulator or through an approval/accreditation process handled by the regulatory agency or some other group (INPO, HPS, NVLAP, etc.). Once the initial approval is granted the continued proficiency testing should focus on the calibration process. The ideal would be to have the facility perform blind calibrations on the same model of ED paralleling the recommendations of Eisenhower (1983) and summarized in Table 3. This could be accomplished by having the facility report the readings for a unit purposely miscalibrated or by using one with a blank display. Periodic on-site visits should be scheduled to review control procedures and program records.

Table 3: Procedures for Performance Evaluation (from Eisenhower 1983)

\begin{tabular}{|c|c|c|c|}
\hline To Evaluate Ability to & Participant Should & Evaluator Should & Evaluation by \\
\hline $\begin{array}{c}\text { Calibrate Dosimetry } \\
\text { Instruments }\end{array}$ & $\begin{array}{c}\text { Calibrate an } \\
\text { Instrument }\end{array}$ & $\begin{array}{c}\text { Calibrate Same } \\
\text { Instrument }\end{array}$ & $\begin{array}{c}\text { Comparison of } \\
\text { Calibration Factors }\end{array}$ \\
\hline--- & --- & -- & -- \\
\hline $\begin{array}{c}\text { Read-out Dosimeters } \\
\text { [Passive] }\end{array}$ & $\begin{array}{c}\text { Calibrate and Read- } \\
\text { out a Dosimeter }\end{array}$ & $\begin{array}{c}\text { Administer a Known } \\
\text { Dose to the Dosimeter }\end{array}$ & $\begin{array}{c}\text { Accuracy of Dose } \\
\text { Read-out }\end{array}$ \\
\hline
\end{tabular}

\subsection{User Responsibilities}

If the ED is to be used for dose of record, the user organization must assume some responsibilities for the successful implementation of the program. The industry recognizes the need for guidance and the MGP Instruments Users Group did form a task team to prepare a document entitled, "Guidelines for Using Electronic Personnel Dosimeters to Perform Dose of Record Monitoring." The guidelines are undated and the effort apparently halted at revision 0 . There is also some guidance included in Appendix B of the draft rewrite of the ANSI N13.27 standard and some guidance was included in NUREG/CR-6354 (Swinth et al. 1995). The following presents some general guidance; specific details must be left to the individual users or industry groups.

\subsubsection{Identification of limitations}

One of the first choices the user must face is the choice of exclusive or shared use of the ED. Unless workers spend a considerable amount of time in radiation areas economics will probably dictate shared use. The disadvantages of shared use are worker ownership and tracking of problems among several workers. However, these are problems that can be effectively addressed and the user must decide upon one or a combination of the choices for his workers. 
As noted in the section on preselection field testing (section 3.3), the user must identify areas and activities where the use of the ED is not appropriate or must be done with caution. This may include welding operations, high dose rate areas, emergency response situations, areas where interference exists (heat sealers, base transmitters, metal detectors, etc.), beta/neutron exposure areas, high humidity areas, rain, areas of direct fission product exposure (off gas treatment areas), etc. In addition, limitations not critical to the primary dosimetry function should be examined. For example, in high noise areas where the alarming function is important to operations one may require an auxiliary alarm (earphones, vibrator). Although most of the limitations will be discovered during the selection process, additional limitations may be identified that will need to be addressed as the program evolves.

Methods of avoiding or controlling these limitations must be identified. This may include posting of areas of high intensity, providing plastic bags for humid areas, posting requirements for beta monitoring and neutron monitoring in specific areas, etc. Another limitation is ensuring that the units are properly activated and read out. This may be handled by two stage access where the badge is activated at one station and an activated ED required to pass a second access point.

\subsubsection{Maintaining ED Performance}

The user must establish methods of maintaining the ED performance. This includes calibrations, performance tests and functional (source) checks. The technical aspects of these items are discussed in earlier sections. The calibration is a critical aspect of maintaining and monitoring the ED performance and it is recommended that the calibration process be accredited. This requires establishing a qualified staff, training, documentation, procedures, a quality system and a record system following guidance in ISO/IEC Guide 25 (ISO 1990). The guidance of ISO/IEC Guide 25 should be extended to the routine performance and functional tests thus assuring quality meeting ISO 9000 standards.

Routine testing must be designed to identify individual malfunctions of concern. The first step in the process is the manufacturer (see section 3.2.4) followed by the quality controls implemented by the user.

\subsubsection{Records System}

The user must establish a records system that will reliably transfer the dose from the ED and store it securely for later transmittal to the NRC. The user should have a system that will permit tracking the identity of the user of each dosimeter and conversely a system that will identify each dosimeter used by a worker. Methods should be in place to routinely test the reliability of the data transfer from the ED and the reliability of summations of data. The system should have some form of back up to ensure that records are not lost by computer failures or accidents (i.e. fire).

The records system should also store a record of all calibrations (both as found data and calibration results) and performance tests. Normally, beyond a record that it was performed, only failure data needs to be kept for source checks. If the ED has internal checks and the user wants to justify a less frequent source checking schedule, records of source checks and internal check warnings should be kept to show that failures were appropriately detected by the internal checks. Records should also be maintained for all training and maintenance activities.

Many systems incorporate an internal histogram feature that is valuable in reconstructing events and providing some indication of inappropriate use or failures. For 
example, a long term constant dose rate may indicate the unit was activated, but not worn. One would expect some variation due to the movement of the worker. Short duration (<minute) peaks may be indicative of interference. Other indications will show when the unit alarmed, peak dose rates, etc. Histogram data should be stored for a short period of time (1-2 weeks) to permit analysis of any questionable data. The histogram is an important tool for identifying questionable data; analogous to the glow curve for the TLD.

\subsubsection{Training and Monitoring of Workers}

Workers should be trained on the appropriate use of the ED. Including proper activation of the units, how it should be worn (ED orientation), protection from r.f.fields, contamination and moisture, alarm reporting and actions, reporting of failures, use of earphones, use of supplemental dosimetry, etc. Workers should be warned of the seriousness of abusing the use of the ED.

Monitoring of the workers and the dosimetry program should be accomplished by the dosimetry and health physics staffs in the field. This should include ensuring appropriate use of the ED, recording of complaints and resolution of problems. Appropriate use would include preventing use as a survey meter, proper protection against moisture, worn in proper orientation, proper readout, activation prior to entering an area, etc. 


\section{Use of the Electronic Dosimeter}

\subsection{Introduction}

The use of the electronic dosimeter can be envisioned in many roles. Obviously the ED can be used solely for secondary dosimetry as it is in many locations today. In this case the demand on the dosimeter performance is low and investigation of discrepancies compared to the primary dosimeter not as important. Formal testing, accreditation of calibrations, etc. are not needed and the present state of the system is adequate albeit improvements in reliability and general performance are still desirable. However, if the ED is to be seriously considered for dose of record applications this scenario is not acceptable and, as a minimum, the use of the ED should be incorporated into a more rigorous system of evaluation and control.

One of the key issues is the need for redundant dosimetry. Redundant dosimetry improves the defense posture in legal cases (Forbes 1995) and is recognized as good practice (Hirning 1996). Although combined dosimetry (passive + active in one package) has been suggested, physically separate devices are preferred to reduce the risk of total loss or damage experienced with a single device. This also suggests that dosimetry should not be combined into a single holder. Separate devices based on a different technology are also preferred since the potential loss of data from the susceptibility of one type of device will be reduced (i.e. r.f. interference). Although not required by regulation, it appears that we are faced with dual dosimetry for radiation workers who enter controlled areas. It should be noted that dual dosimetry is not the practice in all radiation work. The DOE facilities do not uniformly employ dual dosimetry. The use of dual dosimetry practices should be risk based.

Another issue is the measurement of the exposure of visitors or other workers who enter radiation areas, but are not likely to receive more than incidental exposure. Can a graded approach be used to the issue of dual dosimetry? For individuals likely to receive exposures less than $20 \%$ of the annual limits the required accuracy (ICRP 1982) of the measurements is not as stringent (a factor of two). Thus for workers or others likely to receive less than say 150 mrem in a year at 2-5 mrem from an occasional work place entry, several failures of the ED are unlikely to place the recorded dose outside the allowable uncertainties. However, it is still important to leave the impression of competent dosimetry and failures should be rare. For incidental exposures, low energy photon and beta exposures can be ignored without affecting the overall dosimetry results if the basic workplace surveys show that they are a minor component of the dose in the area entered.

\subsection{Dual Dosimetry}

In dual (redundant) dosimetry, the ED can be used as either the primary or the secondary dosimeter. As noted above, when the ED is used as the secondary dosimeter, the control of the ED dosimetry system and the reliability of the system are not as important as if they were used for primary dosimetry. However, efforts should still be made to ensure reliability and to maintain the dosimetry records as long term back up. If the ED is adequately reliable it should be possible to use it to track worker exposures without reverting to 
special processing of TLD or film dosimeters. This could permit a cost saving by permitting centralized processing which would reduce the need for on-site processing.

If the ED is used as the primary dosimeter (dosimeter of record), it should be placed under stringent quality control and the performance of the dosimetry system audited by an independent party. If a processed dosimeter is used as the secondary dosimeter, the processing would not need to be as frequent as at present nor would onsite processing be required. In addition, if the ED becomes the primary dosimeter, in cases where only incidental exposures are anticipated, it may be possible to use the ED as the sole dosimeter. Also present passive dosimeters may not be the secondary dosimeter of choice. For example, DRDs (pencil ion chambers) may become the secondary dosimeter of choice. They are well known in the industry, reliable and inexpensive. Other dosimetry techniques such as optically stimulated luminescence, direct ion storage, etc. may also become useful for secondary dosimetry.

There may be a need for a new type of ED if they are used for dose of record. In the case of visitors, expected incidental exposures, or workers monitored to ensure that exposures remain below the threshold for monitoring, a simple but reliable dosimeter without all of the alarms could be adequate. Beta, neutron and lowenergy photon response would not be important. Adequate uncertainty of dose measurements could be maintained. The down side would be that some of these individuals who are now reported as receiving " 0 " dose could now receive annual doses of several 10 's of mrem.

\subsection{The ED for Record Dosimetry}

In order for the ED to become accepted for dosimetry of record certain issues must be addressed and certain steps taken. Some of these steps are highlighted below:

- The reliability of the ED in general must improve. Significant improvements have occurred in the past few years for the dosimeters likely to be considered for primary dosimetry. The reliability of a few models must improve to the extent that there is little question about their suitability for dose of record. This will help shift the thinking in terms of dose of record. This step is the responsibility of the manufacturers and is expected to evolve through the marketplace.

- Regulatory agencies should develop policy on the suitability of the use of EDs for visitors, incidental workers, and as a demonstration of compliance with monitoring thresholds.

- Control of electromagnetic interference must continue to be addressed. Improvements in immunity, administrative controls and the use of the histogram recording feature to eliminate anomalous readings should be considered.

- Susceptibility levels for r.f. testing need to be addressed in more detail. Many standards use testing levels based on average observed levels in a factory setting. This does not address the colocation of the generator and user instrument as experienced in today's environment. Once reasonable test levels are established, attention can be switched to controlling the source, either through shielding or administrative controls.

- The high dose rate limitation must be addressed. Since this is a concern primarily for high energy photons, incorporation of a passive device that 
could be read out as required may be satisfactory. Suitable devices include present passive dosimeters, devices used for battlefield dosimetry, etc.

- Procedures for control of the performance of the ED must be developed and accepted. Guidelines exist that could be used to develop a program which should be evaluated and approved by an industry organization.

- A standard on test and calibration of electronic dosimeters developed by the stakeholders is needed.

- Although existing memoranda appear to remove concerns over use of the ED for dose of record, regulatory guidance specific to current issues should be documented. This should address both the suitable response of the device (energy range, radiation types), measurement quality control elements and overview. Although third party overview is not required, some users may want to have some elements incorporated into their program to aid in justifying the use of the ED.

- Pilot trials of use of the ED for primary dosimetry should be undertaken by the industry in cooperation with the NRC. The pilot trials should incorporate prototype quality control and third party approvals, if deemed necessary. Industry programs presently exist that could be used for the pilot programs. A NVLAP approved dosimeter should be used as a back up or secondary dosimeter. 



\section{Conclusions and Recommendations}

The electronic dosimeter has shown significant improvements in reliability and capability in recent years. Although the improvements in performance have been across the industry, the performance of available EDs is variable. Thus some models are candidates for dose of record today while others are more suitable for their present use as secondary dosimeters. This rapid evolution of the ED is reminiscent of the early evaluations of the thermoluminescent dosimeter (TLD) which resulted in the displacement of film as the dose of record in many instances. The change was not without technical complications. It is important to recall that other techniques such as exoelectron dosimeters, phosphate glass, etc. did not replace the TLD although they have their unique uses today. An important advantage of the ED in this regard is that it is already in wide use and has some important advantages over TLD or film. Advantages include real time data, precision, history recording (histogram), alarms, and lower detection levels. The real time data availability also has the advantage of involving the worker directly in his own dose reduction activities.

The reliability of several models in terms cf required dose investigation frequency for a period of use is as good as or better than passive dosimeters. However, the period of use is smaller which can result in a greater number of total investigations. Reinvestigations can be simpler due to the short worker history to investigate, the availability of a record of events and dose (histogram), and the short delay in the identification of the problem.
In general the performance of the ED is good for photon radiations above approximately 60 $\mathrm{keV}$. Neutron radiations, beta particles and low energy photons need more attention. One model was designed to measure $\mathrm{Hp}(0.07)$ for low energy photons. Another model has been designed for neutron dosimetry, but is not adequate for consideration as a primary dosimeter (Alberts et al. 1994). However, rapid progress is being made in this area and EDs that will be adequate for neutron dosimetry should be available within 2-3 years (see Appendix A.3). Other limitations of the ED are the poor response at high dose rates and r.f. susceptibility. However, even with these limitations the ED could have many areas of application for primary dosimetry as noted in the report.

Type testing standards are available for the ED and were summarized in section 3.2.3. The standards provide test criteria, but more stringent requirements are recommended for repeatability, reproducibility, drop testing, and r.f. susceptibility testing. A second photon energy category is also recommended. Most of the manufacturers have voluntarily performed type testing on their models and this should be adequate if performed or reviewed by an independent party.

There are several recommended steps that should be taken to move the ED forward as a primary dosimeter. Many of these steps are noted in section 4.3 and recognized by users who are attempting to establish primary dosimetry programs based on the ED. In addressing the specific requirements for dose of record, broad stakeholder involvement should be pursued to ensure a program that is reasonable in meeting the 
needs of the users. With the rapid evolution of the technology it is important that efforts be made develop requirements that will be reasonable in the future. The recommendations are noted below:

- Continued efforts should be made at improving the reliability of the ED and decreasing r.f. susceptibility This is the responsibility of the manufacturer.

- Type testing should be the responsibility of the vendor and be based on available standards. User groups should review the standards and recommend changes in criteria to meet needs in their operations.

- Testing in simulated radiation environments as specified in ANSI N13.11 (ANSI 1993) should be performed along with the type tests and should be the responsibility of the manufacturer.

- A technical group should be formed to recornmend a frequency for retesting by the manufacturer. The group should also address the minimum number of units needed for the testing and their selection (prototypes, production models, etc.). The only purpose would be to detect changes in the design and it may only be needed upon model change.

- A stakeholder group should be formed to develop a standard on the calibration and testing of the ED along the lines of ANSI
N323. This is the logical point of control and should be the basis of any accreditation or oversight efforts.

- Basic procedures for the use of the ED should be developed by an industry group. Although these could be identified in the standard mentioned in the previous bullet, the full scope of the procedures needs to be identified. Procedures for acceptance tests, calibration, functional testing, performance testing, control of ED use, training, maintenance, and records will be needed.

- Although there do not appear to be any barriers to the use of the ED for dose of record, regulatory groups should provide some guidance on their use in terms of demonstrating compliance with monitoring thresholds, and monitoring of radiation types (beta, low energy photons, etc.) that are a small component of the total dose.

- Formal pilot trials of use of the ED for primary dosimetry should be undertaken by the industry in cooperation with the NRC. The pilot trials should incorporate prototype quality control and third party approvals, if deemed necessary. Industry programs presently exist that could be used for the pilot programs. A NVLAP approved dosimeter should be used as a back up or secondary dosimeter. 


\section{References}

10 CFR 20. 1991. U.S. Nuclear Regulatory Commission, "Standards for Protection Against Radiation." U.S. Code of Federal Regulations.

Adams, J., D. Wu, and A Budlong. 1990. Measurement of Electric Field Strength Near High Powered Personal Transceivers. NISTIR 90-3938, U.S. Department of Commerce, Washington. D.C.

Alberts, W.G., E. Dietz, S. Gouldbakke, and H. Kluge. 1994. "Response of an Electronic Personal Neutron Dosemeter." Radiat. Prot. Dosim. 51:207-210.

American National Standards Institute (ANSI). 1981, Reapproved, 1992. Performance Requirements for Pocket-Sized Alarm Dosimeters and Alarm Ratemeters. ANSI N13.27, New York, New York.

American National Standards Institute (ANSI). 1982. American National Standard Safety Levels With Respect to Human Exposure to Radio Frequency Electromagnetic Fields. ANSI C95.1, New York, New York.

American National Standards Institute (ANSI). 1986. "Software Verification and Validation Plans." ANSI/IEEE 1012 - 1986, New York, New York.

American National Standards Institute (ANSI). 1989. "IEEE Standard for Software Quality Assurance Plans." ANSI/IEEE 730, New York, New York.

American National Standards Institute (ANSI). 1989. Performance Specifications for Health
Physics Instrumentation-Portable

Instrumentation for Use in Normal Environmental Conditions. ANSI N42.17A, New York, New York.

American National Standards Institute (ANSI). 1993. Personal Dosimetry PerformanceCriteria for Testing. ANSI N13.11, New York, New York.

American National Standards Institute (ANSI). 1995. American National Standard Performance Criteria for Active Personnel Radiation Monitors. ANSI N42.20, New York, New York.

American National Standards Institute (ANSI). 1997. American National Standard Radiation Protection Instrumentation Test and Calibration. ANSI N323-R1997, New York, New York.

American Society of Mechanical Engineers (ASME). 1989. "Quality Assurance Requirements for Nuclear Facility Applications." ASME-NQA2.

American Society of Mechanical Engineers (ASME). 1990. "Quality Assurance Requirements for Computer Software for Nuclear Facility Applications." ASME NQA-2a, Part 2.7.

Bartlett, D.T. 1993. "Electronic Dosemeters: Use in Personal Dosimetry." Radiat. Prot. Dosim. 47: 335-339.

Bohm, J., and P. Ambrosi. 1990. "Mandatory Type Tests of Solid State Dosimetry Systems as an Appropriate Aid to Quality Assurance in Individual Monitoring." Radiat. Prot. Dosim. 34(1.4):123-126. 
Brown, D.P. 1966. "A Pocket-Size, Signaling, Radiation Dosemeter." Health Physics 12: 943 947.

Clement, R. S. 1995. Evaluation of ANSI $N 42.17 \mathrm{~A}$ by Investigating the Effects of Temperature and Humidity on the Response of Radiological Instruments. LA-12910-MS, Los Alamos National Laboratory, Los Alamos, New Mexico.

Cluchet, J., and H. Joffre. 1967. "Applications of Thermoluminescence Dosimetry in Health Physics." Luminescence Dosimetry. AEC Symposium Series, Vol. 8, CONF-650637, Division of Technical Information, USAEC, Springfield, Illinois.

Delacroix, D., M. Guelin, C. Lyron, and J.P. Ferand. 1995. "Dosicard: On-Site Evaluation of a New Individual Dosimetry System." Radiat. Prot. Dosim. 58:193-199.

Doremus, S.W., and G.A. Higgins. 1994. "PreIrradiation Fade and Post-Irradiation Fade for LiF:Mg,Ti TLD-600 and TLD-700 As a Function of Time." Radiat. Prot. Dosim. 54:119-125.

Eisenhower, E.H. 1983. "Development of a Radiation Measurement Support System." Presented at Ionizing Radiation Measurements Workshop, Regional Radiation Control Training Conference, Park City, Utah, September 20-22, 1983.

Eisenhower, E.H., editor. 1991. Criteria for the Operation of Federally-Owned Secondary Calibration Laboratories (Ionizing Radiation). NIST Special Publication 812, National Institutes of Standards and Technology: Gaithersburg, Maryland.

Erickson, G.L. 1969. A Selectable Alarm Pocket Dose Rate Alarm Dosimeter. DUN-5938, Douglas United Nuclear, Richland, Washington.
Erickson, G.L. 1970. A Selectable Level Alarming Personal Dosimeter. DUN-7027, Douglas United Nuclear, Richland, Washington.

Forbes, J. 1995. Panel Discussion at the Southeast Regional Meeting of the Health Physics Society, Electronic Dosimetry: Active vs. Passive, Atlanta, Georgia, March 3-4, 1995.

Gregory, D.S. 1994. Feasibility Study on Sitewide Use of the Siemens Electronic Personal Dosimeter: Alternative to the Self Reading Dosimeter. WSRC-RP-94-650, Westinghouse Savannah River Company, Aiken, South Carolina.

Grogan, D., R.P. Bradley, and A. Mattioli. 1990. "Uniformity and Stability of LiF Sensitivity-A Review of Fourteen Years' Monitoring Experience." Radiat. Prot. Dosim. 34:99-102.

Health and Safety Executive (HSE). 1990. The Examination and Testing of Portable Radiation Instruments for External Radiations. Health and Safety Services Booklet HS(G) 49, London.

Heinzelmann, M., and R. Schumacher. 1984. "Influence of Chemicals on Unirradiated LiF Thermoluminesce Dosimeter Reading." Radiat. Risk Prot. III:1056.

Hirning, C.R. 1995. "The Increasing Need for Active Dosemeters in the Nuclear Industry." Radiat. Prot. Dosim. 61: 1-7.

Hirning, C.R. 1996. "Selection of a New Dosimetry System: One Utility's Experience." Radiat. Prot. Dosim. 66: 1-4.

Hirning, C.R., P.S. Yuen, and S. Lopez. 1994. Assessment of Siemens Plessey Electronic Personal Dosimeter. COG-94-23, CANDU Owners Group, Toronto, Canada.

Hodgson, L. M., O. W. Cypret and R. R. Culp. 1988."Portable Instrument Reliability at Elevated Temperatures." Proceedings of the $22^{\text {nd }}$ Topical 
Meeting on Instrumentation, South Texas Chapter of the Health Physics Society, San Antonio, Texas, pp. 301-313.

International Commission on Radiological Protection (ICRP). 1982. General Principles of Monitoring for Radiation Protection of Workers. ICRP 35, Pergamon Press, Oxford.

International Organization for Standardization (ISO). 1979. X and Gamma Reference Radiation for Calibrating Dosemeters and Dose Ratemeters and for Determining Their Response as a Function of Photon Energy. ISO 4037-1979(E), International Organization for Standardization, Zurich, Switzerland.

International Organization for Standardization (ISO). 1990. General Requirements for the Competence of Calibration and Testing Laboratories. ISO/IEC Guide 25, International Organization for Standardization, Geneva, Switzerland.

Johnson, M.L. 1993. Evaluation of the Science Applications International Corporation $\mathrm{PH}-4$ Electronic Dosimeter. PNL-8959, Pacific

Northwest Laboratory, Richland, Washington.

Kececioglu, D. and Sun Feng-Bin. 1995. Environmental Stress Screening. Upper Saddle River, NJ: Prentice Hall.

Lacoste, F., and M. Lucas. 1994. "LeSystéme Dosicard." Bull. Can. Radiat. Prot. Assoc. 15:2021.

Lantz, M. W. 1996. "Should Electronic Dosimeters Be Used as Primary Dosimeters?" Radiation Protection Management, 13: pp.28-34.

Lewandowski, M. 1996. "An Investigation of False Positive Dosimetry Results at the Waste Isolation Plant." Presented at 1996 Bicron-NE TLD Users Symposium, Cleveland, OH, October 7-11, 1996.
Lopez, S. 1997. "DMC-2000 Eagle, New Generation Dosimeter." Presented at 1997 MGP User Group Meeting, June 14-20, 1997, Atlanta, GA.

Marshall, T.O., C. Wernli, and R.J. Tanner. 1994. "Performance Requirements of Personal Dosemeters: Can These Be Met by Present and Future Designs." Radiat. Prot. Dosim. 54(1/4):387-294.

Marshall, T.O., D.T. Bartlett, P.H. Burgess, C.S. Cranston, D.J. Higginbottom, and K.W. Sutton. 1990. "Electronic Personal Dosemeters." Radiat. Prot. Dosim. 23(1/4):93-97.

Martin, P. 1996. "NVLAP Accreditation Program for Electronic Personnel Dosimeters." Presented at 1996 Bicron-NE TLD Users Symposium, Cleveland, OH, October 7-11, 1996.

Martin, P. R. 1996. "Laboratory Accreditation Program - Dosimetry." Applications of New Technology: External Dosimetry. Medical Physics Publishing, Madison, Wisconsin.

Martin, P.R. 1994. Ionizing Radiation Dosimetry. NIST Handbook 150-4, U.S. Department of Commerce, Washington, D.C.

Orsini, S., T. Terrana and F. Merluzzi .1988. "Exposure to Radiofrequency (RF) in Industry. Examples of Measurement and Improvement." Radiation Protection Practice, Sydney: Pergammon Press, pp. 473-476.

Piper, R.K. and R.I. Scherpelz. 1997. "Testing the Angular Response of Electronic Personnel Dosimeters." Health Physics 72:S80.

Piper, R.K., C.D. Hooker, J.C. McDonald. and I.S. Deneau. 1993. "Response Characteristics of an Electronic Pocket Dosimeter Against NVLAP/DOELAP Beta and Photon Fields." Presented at the Annual Health Physics Society Meeting, Atlanta, Georgia, July 11-15, 1993. 
Reece, W. D. 1996. "Assessment of Effective Dose Equivalent From Dosimeter Response." Applications of New Technology: External Dosimetry. Medical Physics Publishing, Madison, Wisconsin.

Roberson, P.L., G.W.R. Endres, R.A. Fox, D.L. Haggard, K.K. Holbrook, and L.A. Rathbun. 1984. Spectral and Dosimetric Measurements of Photon Fields at Commercial Nuclear Sites. NUREG/CR-3569, U.S. Nuclear Regulatory Commission, Washington, D.C.

Rotunda, J. 1996. "Integrated EPD/TLD System." Presented at 1996 Bicron-NE TLD Users Symposium, Cleveland, OH, October 7-11, 1996.

Siemens Medical Systems, Inc. 1994. Siemens Electronic Dosimetry. Issue 3. Siemens Medical Systems, Hoffman Estates, Illinois.

Silberberg, J.L. 1994. "Medical Device Electromagnetic Interference Issues, Problem Reports, Standards, and Recommendations." Proceedings of the Medical Devices Bureau (Canada) EMI Round Table (September 1994)

Sorber, R.E., J.A. Twiggs, and N.H. Nei. 1988. "Estimating Low Energy Photon Fractions at Nuclear Power Stations." Radiat. Prot. Management 5:55-59.

Suzuki, S. 1996. "Development and Application of a New Electronic Personal Dosimeter (EPD)." Applications of New Technology: External Dosimetry. Medical Physics Publishing, Madison, Wisconsin.

Swinth, K. L. 1996. "Performance Expectations for Electronic Dosimeters." Applications of New Technology: External Dosimetry. Medical Physics Publishing, Madison, Wisconsin.

Swinth, K. L., E. H. Eisenhower and F. X. Masse. 1988. "The HPS Program for Accreditation of Laboratories for the Calibration of Portable Health Physics Instruments." Proceedings of the $22^{\text {nd }}$ Topical Meeting on Instrumentation, South
Texas Chapter of the Health Physics Society, San Antonio, Texas, pp. 269-274.

Swinth, K.L. 1988. "Radiation Measurement." IEEE Trans. Nuc. Sci. 35:941.

Swinth, K.L. and E. E. Hickey. 1988. "The Response of Health Physics Instruments to Temperature Variations." Proceedings of the $22^{\text {nd }}$ Topical Meeting on Instrumentation, South Texas Chapter of the Health Physics Society, San Antonio, Texas, pp. 346-354.

Swinth, K.L., and J.L. Kenoyer. 1985a. "Evaluation of Draft ANSI Standard N42.17 by Testing." In Proceedings, Workshop on Radiation Survey Instruments and Calibrations. National Technical Information Service, Springfield, Virginia.

Swinth, K.L., and J.L. Kenoyer. 1985 b. "Evaluation of Health Physics Instrument Performance." IEEE Trans. Nucl. Sci. NS-32:923.

Swinth, K.L., J.C. McDonald, D.R. Sisk, I.M.G. Thompson and R.K. Piper. 1995. Performance Testing of Electronic Personal Dosimeters. NUREG/CR-4754, U.S. Nuclear Regulatory Commission, Washington, D.C.

Swinth, K.L., P.L. Roberson, and J.A. MacLellan. 1985. "Improving Health Physics Measurements by Performance Testing." Health Physics 55:197205.

Tawil, R. 1996. "Thermoluminescent Dosimetry." Applications of New Technology: External Dosimetry. Medical Physics Publishing, Madison, Wisconsin.

U.S. Department of Energy (DOE). 1986. Department of Energy Standard for the Performance Testing of Personnel Dosimetry Systems, DOE Laboratory Accreditation Program for Personnel Dosimetry Systems. DOE/EH0027, U.S. Department of Energy, Washington, D.C. 
U.S. Department of Energy (DOE). 1994. Implementation Guide: Instrument Calibration for Portable Survey Instruments. G-10 CFR-835/E1 Rev. 1, U.S. Department of Energy, Washington, D.C.

U.S. Department of the Navy (DON). 1979. Navy Manufacturing Screening Program. NAVMAT P-9492, U.S. Government Printing Office, Washington, D.C.

Van Cauteren, J. and M. Bricoult. 1996. "Introduction of TLD Dosimetry in a Belgian Power Plant." Presented at 1996 Bicron-NE TLD Users Symposium, Cleveland, $\mathrm{OH}$, October 7-11, 1996.
Wernli, C. 1996. "Dosimetric Characteristics of a Novel Personal Dosemeter Based on Direct Ion Storage (DIS)." Radiat. Prot. Dosim. 66:23-28.

White, D. 1995. "Electromagnetic Compatibility: What Is It? Why Is It Needed?" Instruments and Control Systems, January: 65-67.

Whitener, C. 1996. "Evaluation of Irregular Glow Curves and Beta False Positives." Presented at 1996 Bicron-NE TLD Users Symposium, Cleveland, OH, October 7-11, 1996.

Witters, D.M. 1995. "Medical Devices and EMI: The FDA Perspective." ITEM Update 1995 pp. 22-32. 


\section{APPENDIX A}

\section{FOREIGN PROGRAMS}

This appendix contains a summary of information from visits to regulators and manufacturers in foreign countries. Great Britain's Health and Safety Executive was selected since they have approved a dosimetry system based on an electronic dosimeter and Siemens was selected since they manufacturer the only ED designed primarily for dose of record. MGP was selected since based on the survey performed by NEI (Swinth et al. 1995) they account for approximately $73 \%$ of the EDs in the U.S. and have shown a direct interest in dose of record. The visit to IPSN (France) was to look at their regulatory and type testing activities while the visit to Eurisys Mesures (Dosicard) was to look at their recent experience with type testing. Information obtained during an ISO meeting on Germany's initiative toward basing all dosimetry on total uncertainty is included at the end of the appendix. The information is included in the following sections:

- A.1 Health and Safety Executive

- A.2 Siemens Environmental Systems Ltd.

- A.3 Institute de Protection et deSurete Nuclear (IPSN)

- A.4 Eurisys Mesures (Dosicard)

- A.5 Merlin Gerin Provence Instruments (MGPI)

- A.6 Germany 
A.1 Health and Safety Executive (HSE); Bootle, Great Britain (April 21, 1997) (Primary contacts: Dr. J. Gill, J.M.R. Tyler, C.E. Temple)

The Health and Safety Executive (HSE) is associated with the Department of the Environment and has responsibility for the health and safety of workers and the public as affected by industrial activities. HSE approves dosimetry services as required under Regulation 15 of the Ionizing Radiations Regulations (IRR) of 1985 (similar to 10CFR20 in the U.S.). This involves consideration of Regulations 13 (Dose assessment), 14 (Accident dosimetry) and 27 (Contingency plans) of the IRR. The requirements and guidance are expanded in three documents that were revised in 1995/1996 to improve clarity, include experience and to acknowledge the potential use of electronic dosimeters. The documents are: 1 ) "Requirements for the approval of dosimetry services under the Ionizing Radiation Regulations 1985 (RADS), Part1: External Radiations;" 2) "RADS, Part 2: Internal Radiations;" and 3) "RADS, Part 3: Coordination and Record Keeping."

Dosimetry services are approved by the HSE in three categories: (1) External Radiations, (2) Internal Radiations, and (3) Co-ordination and Record Keeping. The approval for external dosimetry does involve a proficiency test that the service seeking approval can obtain through a laboratory accredited for such tests by the United Kingdom Accreditation Service (UKAS; formerly NAMAS, National Measurement Accreditation Service). The proficiency test involves irradiation of five dosimeters at five dose levels using Cs- 137 or Co-60 sources with performance based on the evaluation of the bias and the relative standard deviation. An unqualified pass requires that the bias fall within $\pm 20 \%$ and the relative standard deviation falls within $\pm 10 \%$ for the five groups (tolerance is increased by $5 \%$ for the lowest dose level). Tests are repeated every 18 months, and are not performed for other photon energies or beta radiation. Certification involves an on-site evaluation during which the quality of the services are examined and, most importantly, the performance of the proposed dosimeter is examined. At the present time the examination of the performance is not based on type tests against a standard. However, type test data and other performance data would be examined during the evaluation process while examining evidence showing that the dosemeter is suitable for the environments in which it will be used. As noted in paragraph 35 (b) (2) of the RADS, Part1 document which covers methods of measurement and assessment: "...can be shown by the provision of sufficient evidence from laboratory tests and field trials (e.g. for novel systems) to have an accuracy, reliability and suitability, in the environments in which it will be used, comparable with established techniques..."

Under the HSE arrangement, the records system must be approved and may be separate from the approval for the assessment or dosimetry provider. The Approved Dosimetry Service (Assessment) determines the dose and the Approved Dosimetry Service (Records) maintains the records and reports the worker exposures to the employer and the HSE. It is only classified persons (likely to receive doses $>0.3$ of dose limit) who are subject to the requirements for personal dosimetry, including dose record keeping. Summaries of the doses received by all classified persons are reported to HSE after the end of each year. Doses above 0.6 of the dose limits are notified promptly to HSE. However, as a service to the employer the Service may maintain records of other workers (non-classified) for the employer. Provision is made for the remote reading and transmittal of readings for (electronic) dosimeters to the assessment service.

At the present time only one service is approved for the use of electronic dosimeters. This is the National Radiological Protection Board which maintains its own approved dosimetry service for coordination and record keeping. The certification was granted in August of 1994 and is specific with regard to model of dosimeter (Siemens-Plessey Mk1.0), version of 
software and conditions of use. It is not approved for flash X-ray units, flammable atmospheres, dose to skin near radar units, or beta radiation with Emax less than $0.75 \mathrm{MeV}$. This approval is for electronic dosimeters which are issued to individuals.

Currently a second service using electronic dosimeters is under consideration. Magnox Electric is preparing to apply to operate a dose assessment service out of the Bekeley Centre for use at Magnox nuclear stations, although the service might also be offered for use at other stations, including the PWR station operated by Nuclear Electric at Sizewell B. The approval will be for a newer model of the Siemens-Plessey unit and will be for the pooled usage of the dosimeters. They will not be individually assigned. Recent experience at Sizewell which involved 70,000 readings over a period of approximately 10 weeks resulted in 120 problems. Half of these involved problems with batteries or displays and about 20 would have required a change in records. There is still some question about the value of bothering with skin doses.

Some of the specific points of concern for HSE with regard to use of the electronic dosimeter at a shared service such as Magnox Electric are:

-Establishing confidence in the reliability of the dosimeter

-Re-assessment of doses following a query

-Matching of wearer/dosimeter/issue period

-The possibility of corruption or loss of data

-The radio frequency and microphony sensitivity of the dosimeter

-Maintenance of data integrity at the out-stations by the dosimetry service

-Maintaining integrity of the transmitted data and -The need for multiple approvals.

Some recurring problems have been the bulk and weight of the electronic dosimeter and recurring problems with breakage of displays. It was felt that it was important that users pay attention to susceptibility of the units to electrostatic discharge. Although current approval activities are centered on the SiemensPlessey unit, other electronic dosimeters are under consideration by services.

\section{A.2 SIEMENS ENVIRONMENTAL} SYSTEMS LTD. Poole, Great Britain, April 22,1997

(Primary contacts: Richard LeFleming and Robert Fletcher)

Siemens markets their electronic dosimeter world wide and at present it is the only dosimeter with government approval (Great Britain) for primary dosimetry. Their dosimeter is commonly known as the Electronic Personal Dosimeter, EPD (trade marked) and uses three detectors to provide both $H_{p}(10)$ and $H_{p}(0.07)$. This is the only electronic dosimeter widely available that provides both quantities. As noted in the previous section the NRPB is approved by the HSE to use the EPD for dosimetry within NRPB facilities and Magnox Electric is preparing to operate an approved dosimetry service for nuclear power plants using a newer model of the EPD. Siemens is involved in developing the software needed to reliably read, protect, and transmit the EPD readings.

Type testing of the units has reportedly been done at NRPB and evaluated against criteria in the IEC 1283 standard, (Radiation Protection Instrumentation-Direct Reading Personal Dose Equivalent (Rate) Monitors-X, Gamma, and High Energy Beta Radiation). A copy of the type test information was not made available. In addition, type tests have been performed in Czechoslovakia, Slovak, and Germany (tests for use as an alarming dosimeter). Approval or approval in principal for use as a "legal" dosimeter has been granted by Norwegian, Slovak and Italian governmental agencies.

Routine testing consists of prescreening of components and assemblies plus electronic functional tests on the circuit boards. Siemens mounts components on the boards (surface mount technology) and performs their own testing. Siemens is ISO9001 certified. Each unit is formally tested for microphony sensitivity. Units 
are not tested for radio frequency (R.F.) susceptibility since this is felt to be well characterized. Siemens has made changes on a newer model (MK1.2 (EMC)) that reduces the R.F. susceptibility. However, inherent in the design is a region of susceptibility around 2 $\mathrm{MHz}$. The model is immune to fields of about $100 \mathrm{~V} / \mathrm{m}$ over most of the frequency range and this can be improved by over an order of magnitude by the use of a special shielding pouch.

The EPD performs circuit self checks by injecting electronic pulses into the circuit. The units also count the radiation background to check the detectors and the electronics. The software for the system is not made available to users and as noted above in presently approved systems the specific version of the software is noted in the approval process. Siemens provides user training for limited servicing of their units. Repair of damaged cases, displays, or clips and exchange of batteries are examples of customer servicing that is permitted.

Calibration of the EPD is performed in a specially fabricated fixture that uses a sequence of Cd-109, Cs-137, and Am-241 photon sources plus a Kr-85 beta source for calibration of each unit. A sequence of irradiations are used to iteratively establish 12 variables on which the calibration depends. EPDs termed "golden" EPDs that have been calibrated on open ranges at the NRPB are used to check the calibrator on a periodic basis. [This is a process recognized for tertiary level calibrations in the Health Physics Society Laboratory Accreditation Criteria.] The NRPB has done a one year follow up test on the units that they use for their accredited service with Cs-137 and did not detect any drift in calibration. An irradiator is available which uses Am-241 and Cl-36 sources for periodically checking the calibration of the units. Siemens recommends that the users establish a set of "golden" EPDs to periodically check the calibration of the irradiator. A special calibration has been done to normalize the energy response to $\mathrm{Co}-60$ for one customer; for another customer the tolerance for the beta calibration factors was tightened resulting in improved field performance.

Due to the stability of the units and the method of calibration and characterization, the manufacturer does not see a need for repeated third party performance tests by each user.

\section{A.3 INSTITUT DE PROTECTION ET DE SURETE NUCLEAR (IPSN), Fountenay-Aux- Roses, France, April 24, 1997 \\ ( Primary contacts: Dr. J.M. Bordy, Dr. J.L. Chartier, Dr. M. Chenmtob, Dr. A. Rannou, Dr. J.F. Bottollier-Depois)}

The IPSN is a division of the CEA (French Atomic Energy Commission) and responsible for the overall French radiation protection programs. They perform research and development for radiation protection and coordinate the overall programs. In addition to discussing the overall regulatory climate for dosimetry and testing, discussions were held on the development of neutron detectors intended for use in electronic dosimeters. The topics are discussed separately below.

\section{$\underline{\text { Regulatory Climate }}$}

At the present time there are three laboratories in France that are performing personal monitoring. Film is the standard dosimeter, but the bases for measurements varies (air kerma, tissue below $300 \mathrm{mg} / \mathrm{cm} 2$, etc.). I briefly met Dr. Alain Rannou (Head, Service de Dosimetrie) who is on committees to determine how dosimetry will be handled in France using film or any other system. Under a European community directive all member countries must use the same measurement quantities and same radiation limits by May, 2000. This will impact how electronic dosimeters are handled in the future. At the present time legal records are based on film and laboratories are accredited through "OPRI" which is a division of the Ministry of Health. 
Type testing is performed for electronic dosimeters and other instruments through the Centre Technique d'Homologation de I'Instumentation de Radioprotection (CTHIR). The tests are paid for by the manufacturer and include a comprehensive report which includes comparisons against the relevant IEC and ICRU requirements. The CTHIR is managed by Maurice Chemtob and the evaluation/qualification process is one of coordinating tests through various facilities within France. Although the CTHIR is not an accredited operation, many of the facilities that they use are accredited. CTHIR will become accredited and after this change the process will become one of certification and the manufacturers will be monitored. If the manufacturer changes model numbers, he is expected to redo the entire test process, but if only selected components are changed only the potentially affected performance parameters must be evaluated. Testing is generally performed with a single instrument and at present there is no regulation in France requiring "homologation." The French committee for calibration and test accreditation is "COFAC" which is under the Ministry of Industry and bases its activities on ISO/IEC Guide 25 and the European standard EN45001. The National Bureau of Metrology (BNM) is responsible for the technical aspects of accreditation, but relies upon several laboratories for the physical measurements. These various laboratories maintain the radiation (and other standards) standards and are accredited.

Test reports were obtained for the DOSICARD. In several instances the tests extend beyond the ranges required in the IEC standards, but the performance over the range of the relevant standard is clearly indicated. The tests are not presented as pass/fail, but indicate the measured performance which in a couple of instances did not comply with the standards.

\section{Neutron Detectors}

The French are performing important research that will lead to compact neutron dosimetry systems that should be suitable for electronic dosimetry. Dr. Jean-Paul Bordy is leading these efforts and explained many of the current efforts. Efforts are underway on a silicon diode based detector and a tissue equivalent proportional counter, TEPC. The TEPC promises to be about 10 times as sensitive as the silicon based detector and will have an improved energy response. A prototype silicon detector based pocket dosimeter is expected by the end of the year, but it will have about a factor of 8 change in response with energy. Additional information is available in (RPD, $70 \mathrm{pp} .73-78$ (1997)). The TEPC is a multi-cellular arrangement and a prototype is forecast for the middle of 1999 . They are targeting a weight range of $350-400 \mathrm{~g}$ with a size somewhat larger than current electronic dosimeters designed for photons. The research is extensive and important to the radiation protection community.

\section{A.4 EURISYS MESURES, Loches, France} April 25, 1997

(Primary contacts: G. Darmon, T. Pochet, P. Lecuyer, J.C. Samier)

Eurisys Mesures produces several models of nuclear instrumentation including the Dosicard electronic dosimeter which is one of the smallest electronic dosimeters available. The unit has all of the features of larger units and under normal operating conditions will operate on a standard battery for one year. The dosimeter is contained in a separate sealed pouch with clip during use and does not have to be removed for reading either manually or with an automated reader. The facility is ISO 9001 certified and will achieve ISO 9002 certification in a few months. Surface mount technology is used in the fabrication of the units and the mounting of components can be accomplished at the rate of about one board per minute. The boards are subjected to electronic tests with a typical reject rate of a few percent. Rejects may be due to components or assembly and are reworked or rejected. Following assembly the units are calibrated on the production floor with a Cs-137 source in a special calibration bench. The calibration is automated with units irradiated to 
about $40 \mu \mathrm{Sv}(80 \mu \mathrm{Sv} / \mathrm{h})$ for the calibration. During production approximately 5 dosimeters per day are tested on Eurisys Mesures calibration range with Cs-137. The calibration range is an open range with collimated sources, a remotely controlled positioning cart, and complete remote operation and is comparable to a secondary laboratory facility. The units are stored and retested before shipping; microphony tests are performed on a sampling basis. The company has not had units returned due to electronic failure, but has had some units returned that were physically damaged.

The dosimeter design was tested by the CTHIR to define its response and compare its performance with applicable standards (IEC). The tests are reported in test reports CTHIR/93091 and supplementary report CTHIR/94-091C. The supplementary report verifies that a variation in response with humidity was corrected. A separate report provides information on electromagnetic and electrostatic performance of the unit. The DOSICARD did comply with applicable standards although some radiofrequency susceptibility was noted at high frequencies $(800 \mathrm{MHz})$.

The Dosicard is used throughout France and at selected laboratories world wide. The Dosicard stores incremental radiation dose histories which are useful in training workers and in resolving any anomalies in worker exposures. The system and some field testing is described in Radiation Protection Dosimetry, 58. Pp. 193-199 (1995).

\section{A.5 MERLIN GERIN PROVENCE} INSTRUMENTS, Lamonon, France April 28,1997

(Primary contacts: J.P. Guillemot, P Martin, F. Schultz, S. Lopez)

Merlin Gerin Provence (MGP) manufactures several types of health physics instruments including electronic dosimeters at its facility in southern France. Type testing of the ED has reportedly been done by the CTHIR and tests have also been done by the French army and the NRPB. Currently tests are being done by a laboratory in the US and a partial report of the tests has been obtained.

MGP is ISO 9001 certified. Surface mount technology is used on the electronic dosimeters, but this step is contracted to a company that specializes in producing surface mount boards. Electronic function tests for the boards are defined by MGP. The company samples and tests components and assemblies. Unit are tested for microphony and radio frequency interference. The displays of the assembled units are tested and each unit is calibrated using Cs-137 as the primary source (special calibrations can be done with Co-60) and Am-241 as a check. Following assembly and calibration the units are operated for a burn-in period to ensure that they are operating properly.

The calibration is performed by an automated assembly that uses attenuators to permit three dose rates (Cs-137) for the calibration. MGP is presently seeking French accreditation (equivalent to NIST) for their calibrations. They have found that the electronic dosimeter is very stable and does not change in performance (calibration) unless the electronics change. The standard acceptance criteria for the calibrations is $\pm 5 \%$ for the Cs- 137 source and $\pm 20 \%$ for the Am- 241 check. The tolerance on calibrations can be tightened to about $3 \%$ and some customers have used a $2 \%$ tolerance. Traceability is maintained through three reference dosimeters (golden dosimeters) calibrated to a known standard (linked to the Bureau National de Metrology, BNM) located in the French army labs. In the instances where there have been differences between the conventional dosimeters and the electronic dosimeters, investigations have shown that the conventional dosimeters were out of calibration. MGP does recommend periodic calibration of the units and does market calibrators that can be used to check the calibration. The customer does not have access to the ${ }^{241} \mathrm{Am}$ calibration factors which define the energy response. Counting background along with counting of periodic 
light pulses on the detector are used to ensure that the unit continues to operate correctly.

The user can perform some services on the ED and MPGI in Atlanta, Ga. has an INPO approved training program. Batteries, power supplies, clips, and cases are some of the user serviceable parts. The users can also modify operational parameters the software, but this is limited to parameters that will not affect the type test performance of the ED. Servicing the detection subassemblies and modifying the calibration software are not permitted. If MGP were to modify the $\mathrm{ED}$, the customer would not be notified if the change did not affect the specifications or the type testing performance. However, if changes were to affect performance the customers would be notified and upgrades performed if necessary. The Atlanta facility of MGP is 10CFR50, appendix B certified and deficiencies under part 21 would be reported as required.

MGP has developed field experience that has led to changes in the EPD. Cases were ruggedized and proven to survive a $1.9 \mathrm{~m}$ drop test. They are going to larger scale integration of components to improve reliability and have added a check sum feature to the software to ensure that the data does not change. They do perform "beta" testing of new designs with selected customers prior to marketing of new designs.

Testing for energy response has been performed on 10-20 units several times and they observed minor changes in the curves, but the basic shape is the same. The units are shielded to over $100 \mathrm{~V} / \mathrm{m}$. The ED will store doses for small intervals ( 1 minute) and these increments can be examined for anomalies such as spikes due to $R F$ interference, constant elevated doses indicating stationary placement in a radiation field, etc. The stored history also includes flags for alarms and removal of batteries. A record of the dose can be retrieved from the EEPROM after total failure of the ED.

\section{A.6 GERMANY}

(Primary Contact: Dr. Peter Ambrosi)

One goal of the European Community (EC) is to ensure that all countries use the same quantities and units plus the same limits for radiation protection purposes. This will permit consistent tracking and reporting of worker exposures within the entire community. Compliance is scheduled for the year 2000 . When Germany makes this transition they also expect to base their Pattern Approvals for dosimetry systems on total uncertainty. A Pattern Approval is similar to a type test and involves evaluation of influence quantities and evaluation of general system performance. The system will apply the same criteria (as applicable) to all dosimetry systems including EDs and conventional systems such as film.

Draft requirements by the PTB provide detailed requirements, including methods of determining the overall uncertainty, the maximum deviations for various influence quantities in terms of both the dosimeter and the overall system. The square of the overall uncertainty is taken as the sum of the squares of the maximum variation of the influence quantities, the maximum deviation from linearity and three times the square of the variation coefficient of a sample. The allowable uncertainties depend on the dose as determined by the so called "trumpet" curve. The trumpet curve is designed to permit an uncertainty of a factor of two in results at low doses and approximately a factor of 1.5 at annual dose limits as recommended in ICRP35. The pattern approval is independent of the calibration and is based on reference conditions. The response under reference conditions is required to be within $40 \%$ except as modified by the trumpet curve at low doses.

Testing of influence quantities includes photon energy and direction of incidence, dose rate, temperature and humidity, sunlight, mechanical shock and vibration, storage in water (extremity dosimeters only), air pressure, dosimeter position [geotropism], and, finally, 
electric and magnetic interference. Tests for sunlight, air pressure and geotropism are only performed on systems where their influence cannot be excluded. The shock test is severe; corresponding to $500 \mathrm{~g}$ for $1 \mathrm{msec}$. Energy and angular dependence are treated as dependent variables with measurements of energy dependence performed at various angles to determine the maximum variation. This results in a fairly large series of measurements. [The quantities are recognized to be dependent variables and most type testing standards require angular testing at two or more energies.] Temperature and humidity are also treated as dependent variables.

Detailed requirements are given for the electromagnetic tests and are based on specific international and national standards. Additional specific RF immunity requirements of $20 \mathrm{~V} / \mathrm{m}$ at $0.9 \mathrm{GHz}$ and $15 \mathrm{~V} / \mathrm{m}$ at $1.8 \mathrm{GHz}$ are given for the ED. This is based on field intensities at $30 \mathrm{~cm}$ for commonly used mobile radiotelephones.

[Note: These intensity values will approximately triple at $10 \mathrm{~cm}$.

The verification ordinance will permit a maximum permissible error of $20 \%$ on the reported dose during the verification process. The verification process only verifies that the calibration of the individual dosimeter is done correctly by the manufacturer. The $20 \%$ is in comparison with the correct value (conventional true value) under reference conditions. 


\section{APPENDIX B \\ OBSERVATIONS ON ED PERFORMANCE}

The following lists items noted in the article by Lantz (Lantz 1996) with an observation. In several instances the observation refers back to sections of the report. It is important to note that the subject of the comment in the article does not always track directly with the highlighted concern. Thus the responses, in some instances, may not appear to track the expressed concern. Following are the major points and a related observation:

- Variable PIN diode energy response See section 2.2 of report.

- Poor angular response of electronic dosimeters

See section 2.2 of the report.

- Some EDs have been noted to mechanically fail (i.e., in need of repair or replacement) at a significant rate: up to $30 \%$ per year.

See section 2.2 of the report.

- The data loss rate for electronic dosimeters is higher than for passive dosimeters. See section 2.2 of the report.

- The speakers for the alarms have been known to fail at very predictable rates and the speaker checks within the ED readers may not be $100 \%$ effective.

- The rate alarm feature of some $E D$ histograms is designed poorly.
- Dose rate measurements from one type of $E D$ have been found to be inaccurate below $200 \mathrm{mR} / \mathrm{h}$

These have little to do with the dose of record and will be taken care of by the market place. Accuracies at low dose rates can be expected to be poor due to the need to accumulate statistically significant data unless some averaging technique is employed which will in turn mask abrupt changes in the dose rate. Poor dose rate accuracy (long response times) is also an issue with survey instruments at low dose rates.

- EDs are generally much larger and heavier than passive dosimeters.

Although this is a problem the units continue to get smaller and lighter and again this will be resolved in the market place.

- Certain histogram processes need improvement before they can be considered as a strong feature in dose recreation.

The histogram does provide a technique to identify abrupt and unexpected changes in dose rate such as spikes from electronic interference. Although long integration times will tend to mask such spikes, time intervals as short as $6 \mathrm{sec}$ are available on the market. Again the market place will resolve such issues.

- Very little is published in peer reviewed journals about ED response and battery voltage. 
This is a problem and we need to encourage users to submit data on the performance of their EDs to peer reviewed journals. There is a fair amount of data that has been generated on the performance of the electronic dosimeter, but a lot of it has not undergone rigorous analysis and peer review.

\section{- ED users may not be completing proper acceptance testing.}

As noted in Swinth et al. 1995 routine tests by the manufacturer and acceptance testing of units by the user are important to ensuring the continued performance of the electronic dosimeter. (see section 3.4 of this report).

- The resources of the manufacturers are being challenged by the efforts to have EDs accepted as dose of record.

The manufacturers do focus on customer needs. Add on alarm enhancements and smaller EDs are entering the market place. Again these enhancements do not relate directly to performance for dose of record applications.

- Some users seem to prefer EDs over TLDs because EDs "just work."

This is a value statement and must be resolved by the users.

- ED filters may have been designed to reduce radiofrequency interference ( $R F I$ ) problems, but not to provide proper photon energy compensation.

It appears that the author is confusing an energy compensation filter with RF shielding. It appears that in the example cited the filter might lead to an undesirable angular dependence. Type testing is needed to resolve this issue.

- Most EDs are large, single element dosimeters.

- Most EDs do not provide any indication of beta or neutron exposure.
It is true that the industry generally uses discriminating (multi-element) dosimeters. However, the need for discriminating detectors is questioned by some users and when the radiation qualities are adequately known it may not be necessary to issue discriminating detectors to all workers.

- The population of EDs in use today is very new.

It is true that new technology brings with it new problems and that aging problems of the current population of dosimeters are unknown. This is an issue that must be resolved by field experience. It is doubtful that replacement of units with newer models will have a serious impact on the quality of the data if due care is used in deploying and using the electronic dosimeter.

- Could a new dosimeter on the horizon (i.e., an ED/TLD) be the answer to all of our problems.

The current interest in electronic dosimetry will enhance the interest in new technology and should be encouraged by the active interest in that technology.

\section{- ED problems may be an unspoken truth.}

Although manufacturers and users often do not want to broadcast their problems, it appears that most manufacturers are making an honest effort at resolving problems that are identified by them or their customers. These issues will be resolved by the market place. In the case of dosimetry of record, problems which affect dose data will need to be identified and all users (and regulators) notified so that proper corrective actions can be taken to resolve the issue.

- Magnetic fields have been known to turn some EDs off.

See section 2.2 of the report. 
- Histograms produced by some EDs have indicated that dose resets may have occurred.

If the dosimeters truly reset before the dose was recorded this is an issue that must be studied further and resolved.

- ED internal electronic checks are questionable.

See section 2.2 of the report.

- EDs are spiking or scrolling to high and low doses.

- High ED dose rates are occurring throughout the industry.

See section 2.2 of the report.

- Unusual performance test failures have been discovered without a determination of the cause.

See section 2.2 of the report.

- Simple occurrences such as keys rattling in front of the dosimeters, pen tapping on the case, dosimeters being dropped or squeezed, RFI, magnets and microwaves have disrupted ED measurements.

See section 2.2 of the report.

- ED users may not be investigating the high rates of "AS FOUND" failures in their regular performance tests.

The calibration of examined EDs is very stable and for these models "as found" investigations should be rare. The marketplace will eliminate EDs with high reinvestigation rates.

- Most facilities are using the EDs in a pooled environment.

The pooled environment is the only cost effective method of deploying the units in a large facility with a large work force. Computer technology should be readily capable of tracking EDs, users, calibrations, source tests, reinvestigations, service records, and adding doses from the various EDs used by a worker.

- Facilities have sent EDs and TLDs to the NVLAP proficiency testing laboratory (PTL) to resolve their differences.

The author implies that the laboratory did not detect differences and that differences in field use were due to differences in energy or angular response. Such differences need to be resolved. However, large scale comparisons in the field have shown that for several models the differences are only a few percent.

- Increasing the chirp rate on one type of ED caused them to underrespond by $75 \%$ See section 2.2 of the report.

- One version of an ED, after encountering an $120 \mathrm{mR} / \mathrm{h}$ field, continued recording at that rate even though the ED had been removed from that field.

As noted in the article this problem was corrected by the manufacturer.

- Failures of the ED control software at the $R C A$ entrance have been found.

See section 2.2 of the report.

- $\quad P I N$ diode detectors may be angular dependent.

All dosimeters should have an angular dependence to correctly measure effective dose equivalent. If the response from the rear is substantially lower the dosimeters should be labeled to ensure that they are worn correctly.

- Overall ED angular dependence can be significant.

This is correct and the impact of the angular dependence must be evaluated. This does not appear to be that significant of a problem if the comparison study results are to be believed. The problem is not detector size since the overall area is not substantially different from a TLD chip. 
However, the sensitive depth may affect the angular response. See section 2.2 for more details.

- Although EDs are calibrated to equate to TLDs and pocket dosimeters in laboratory irradiations, the majority of EDs read lower in field exposures.

See section 2.2 of the report.

- Large dosimetry devices need to be tested for angular dependence at all angles and more energies.

Type testing should be performed on all dosimetry devices, but needs to be interpreted in terms of the probable exposure patterns. A serious underresponse over a small solid angle may have a negligible impact on overall dosimetry results since the exposure is most likely to average over a series of solid angles simply as a result of the movement of the worker or the presence of extended sources. As noted by Lantz (1996) extended sources may be the most common source term.

- Are EDs being used by flouroscopists?

Probably, but their use needs to be evaluated in terms of their known responses and the exposure conditions in the work environment. Some models may be entirely adequate for this application, but there is also a dose rate issue that must be considered.

- External effective dose equivalent. See section 2.2 of report.

- The ED algorithms may not be known by the users.

The reason that the algorithm needs to be known are not clear. The user should not change the basic algorithm since it would take a very experienced programmer to make such changes without introducing problems. The situation on present EDs is not the same as passive dosimeters where the user may want to change the algorithm to better model his particular radiation fields. The user does need to know the version of the software that is in use and should have some assurance that the software is not changed since this could affect type test and field evaluation test data.

\section{- ED microprocessor versions will evolve and change.}

The manufacturer should make the user aware of such changes by changing the model number if it will impact performance. The manufacturer should also keep a record of such changes and documentation that shows the change will not change performance or, alternatively, how it changes performance.

- EDs may be asked to process too much

- Some ED algorithms prioritize dose rate ahead of the dose calculations.

The loss of dose data is unacceptable if the

ED is to be used for the dose of record. Such problems must be identified and corrected.

Accuracy of the dose rate data is important, but such problems will be resolved in the marketplace.

\section{- There is no certification program for new dosimeter designs}

There is no certification program for any (passive or active) dosimeter designs and within the U.S. type testing or pattern testing have not been promoted or required by any regulatory agency. If such a change is promoted it should apply to all technologies equally. This approach is under development in Germany by basing requirements on the total uncertainty of a measurement process as demonstrated by pattern testing.

\section{- Are facilities using EDs for Dose of Record (i.e., Dose of Record vs Non-Required Monitoring)?}

The question is whether a device used to confirm that worker exposures are below the 
level where monitoring is required (500mrem) is a primary dosimeter. If the device is used to report a dose for the individual it should be considered a primary dosimeter. However, it should be noted that the expectations for such a dosimeter are not as stringent as at higher doses. ICRP 35 recommends an accuracy of a factor of two at levels of $1 / 5$ th of the annual limit.

\section{- Do EDs have to be tested under NVLAP?}

The way the regulations are presently written they do not apply to EDs. The ED is not a processed device and operates in a manner similar to a pencil ion chamber which is excluded. The ED does process the signal from the detector(s) in a manner similar to any other radiation survey instrument, but apart from the calibration is not under the direct control of any processor. This is different than the case of the passive device where the processor establishes the processing parameters.

- Some facilities have volunteered for NVLAP accreditation of their EDs, but were only tested in Category IV, high energy photons. If justified by the radiation conditions in the facility such testing may be adequate. However, other users have tested in the other categories and performance for some models has been good.

- Dosimetry is not always issued just because it is required by regulations, it is issued because our industry desires that workers have confidence in the measurement of their doses, even at low doses.

In this case the ED should prove superior since it measures to less than $10 \%$ of the limit of the passive dosimeters and provides the worker with a direct readout. This allows the worker more direct monitoring and control of his own risks.

- A draft NUREG that was to be the performance testing document for EDs was primarily a phone survey of users and a listing of vendor literature.

This is very misleading. The report was to be an interim type testing document. The term performance was used in the broadest concept in the document and was meant to include all components of performance including type testing. An industry conducted survey (NEI) was used to gather information on needs with dosimeters and no phone surveys were conducted. Data from manufacturers, information from peer reviewed literature and published reports along with the NEI survey were used to generate testing criteria and methods presented in the report. Under company and NRC policy it was not possible to include "hearsay" events or information that the source did not release for publication. Some of the reviewed literature included type test data on EDs. Performance and maintenance issues were addressed in the document to make the process complete.

- Is NVLAP as effective as it once was? The original NVLAP program was developed to address a serious issue with performance of personnel dosimetry by processors. From the original testing to the present, the performance of processors has improved substantially. Interest has waned because the perception is that dosimetry is adequate and the present process is an expensive method of monitoring the continuing process. It is agreed that the effectiveness of the program should be reviewed.

\section{- Immediate dollars seem to be driving decisions}

If EDs continue to improve at the same rate they will surpass the present TLDs in performance within a few years while adding technological innovations that will improve the cost effective protection of the worker. The question of maintaining the TLD as a supplemental dosimeter is a separate issue and will probably be evaluated on cost. Many factors 
will be important such as central processing, new materials, etc.

- Where are the cost savings?
It is agreed that manufacturers and users should evaluate the costs of various options to design a cost effective monitoring program. 


\begin{tabular}{|c|c|}
\hline $\begin{array}{l}\text { U.S. NUCLEAR REGULATORY COMMISSION } \\
\text { BIBLIOGRAPHIC DATA SHEET } \\
\text { (see instructions on the reverse) }\end{array}$ & \multirow[t]{2}{*}{ NUREG/CR-6581 } \\
\hline 2. TITLE AND SUBTITLE & \\
\hline \multirow{3}{*}{ Considerations in the Application of the Electronic Dosimeter to Dose of Record } & DATE REPORT PUBLISHED \\
\hline & \begin{tabular}{|c|c|} 
MONTH & YEAF \\
December & 1997
\end{tabular} \\
\hline & $\begin{array}{l}\text { 4. FINOR GRANT NUMBER } \\
\text { W6 } 761\end{array}$ \\
\hline \multirow[t]{2}{*}{$\begin{array}{l}\text { 5. AUTHOR(S) } \\
\text { K. L. Swinth }\end{array}$} & $\begin{array}{l}\text { 6. TYPE OF REPORT } \\
\text { Technical }\end{array}$ \\
\hline & 7. PERIOD COVERED (Inclusive Dares) \\
\hline
\end{tabular}

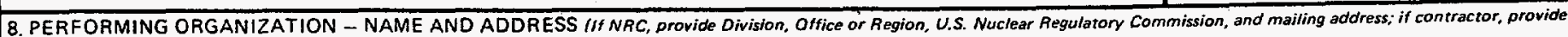
name and mailing address)

Swinth Associates

2177 Cascade

Richland, WA 9.9352

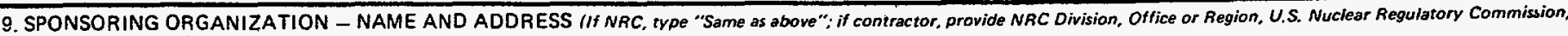
and mailing address.)

Division of Regulatory Applications

Office of Nuclear Regulatory Research

U. S. Nuclear Regulatory Commission

Washington, DC 20555-0001

10. SUPPLEMENTARY NOTES

D. Nellis, NRC Project Manager

11. ABSTRACT (200 words or less)

This report describes considerations for application of the electronic dosimeter (ED)as a measurement device for the dose of record (primary dosimetry). EDs are widely used for secondary dosimetry and advances in their reliability and capabilities have resulted in interest in their use to meet the needs of both primary and secondary dosimetry. However, the ED is an active device and more complex than the thermoluminescent and film dosimeters now in use for primary dosimetry. The user must evaluate the ED in terms of reliability, serviceability and radiations detected its intended application(s). If an ED is selected for primary dosimetry, the user must establish methods both for controlling the performance of the ED to ensure long term reliability of the measurements and for their proper use as a primary dosimeter. Regulatory groups may also want to develop methods to ensure adequate performance of the ED for dose of record. The purpose of the report is to provide an overview of considerations in the use of the ED for primary dosimetry. Considerations include recognizing current limitations, type testing of EDs, testing by the user, approval performance testing, calibration, and procedures to integrate the dosimeter into the users program.

12. KEY WORDS/DESCR!PTORS (List wards or ghrases that will assist researchers in lacating the report.)

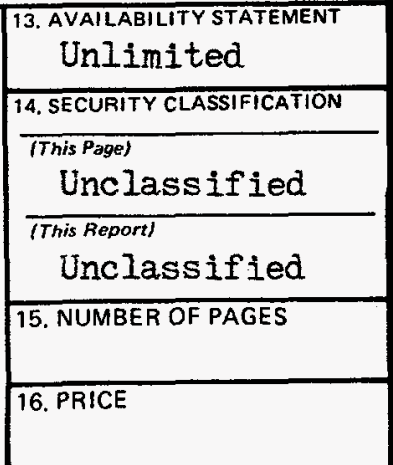

